\title{
Reversed impacts of the Arctic oscillation on the precipitation over the South China Sea and its surrounding areas in October and November
}

\author{
Tianyun Dong ${ }^{1,2} \cdot$ Wenjie Dong ${ }^{1,2} \cdot$ Taichen Feng $^{3} \cdot$ Xian Zhu $^{1,2}$
}

Received: 1 March 2020 / Accepted: 12 September 2020 / Published online: 9 October 2020

(c) The Author(s) 2020

\begin{abstract}
The reversed impacts of the Arctic oscillation (AO) on precipitation over the South China Sea and its surrounding areas (SCSA) in October and November during 1979-2014 are investigated. The correlation coefficients between AO and the precipitation in October and November are 0.44 and - 0.31, which are statistically significant at the $99 \%$ and $90 \%$ confidence levels, respectively. In October (November), the specific humidity exhibits obvious positive (negative) anomalies in the SCSA, and an upward (downward) airflow moving from ground to the upper troposphere (1000-150 hPa) between $10^{\circ} \mathrm{N}$ and $30^{\circ} \mathrm{N}\left(10^{\circ} \mathrm{N}\right.$ and $\left.20^{\circ} \mathrm{N}\right)$ is observed with more (less) cloud cover. Moisture budget diagnosis suggests that the precipitation's increasing (decreasing) in October (November) mainly contributed by zonal moisture flux convergence (divergence). Furthermore, the Rossby wave guided by westerlies tends to motivate positive geopotential height in the upper troposphere over approximately $20^{\circ}-30^{\circ} \mathrm{N}, 40^{\circ}-80^{\circ} \mathrm{E}$ in October, which is accompanied by a stronger anticyclone in the Arabian Sea region. However, in November, the wave train propagating from the Arabian Sea to the Bay of Bengal is observed in the form of cyclones and anticyclones. Further analysis reveal that the AO in October may increase precipitation through the southern wave train (along the westerly jet stream from North Africa to the Middle East and South China). Moreover, air-sea interactions over the North Pacific might also generate horseshoe-shaped sea surface temperature (SST) anomalies characterized by positive SST in the central subtropical North Pacific surrounded by negative SST, which may affect the precipitation in the SCSA. Ensemble-mean results from CMIP6 historical simulations further confirm these relationships, and the models that can better simulate the observed positive geopotential height in the Arabian Sea present more consistent precipitation's increasing over the SCSA in October.
\end{abstract}

Keywords Arctic oscillation $\cdot$ Precipitation anomaly $\cdot$ Climate change $\cdot$ CMIP6

\section{Introduction}

Thompson and Wallace (1998) used the empirical orthogonal function (EOF) analysis method to study the SLP poleward of $20^{\circ} \mathrm{N}$ and found that the first EOF mode shows reversed phase between the mid-latitude and Arctic regions.

Wenjie Dong

dongwj3@mail.sysu.edu.cn

1 School of Atmospheric Sciences, Sun Yat-sen University, Zhuhai 519082, China

2 Southern Marine Science and Engineering Guangdong Laboratory, Zhuhai 519082, China

3 College of Atmospheric Sciences, Lanzhou University, Lanzhou, China
This pattern is named the Arctic oscillation (AO). Subsequently, a lot of studies reveal that the AO not only has significant impact on climate change in mid- and high-latitude areas, such as North America (Hurrell 1995; Hurrell et al. 1997), Europe (Rodwell et al. 1999; Thompson and Wallace 2000; Cullen et al. 2002; Bader et al. 2011; Luo et al. 2014, 2016a, b) and East Asia (Gong et al. 2001; Wu and Wang 2002; Jhun and Lee 2004; Watanab 2004; Jeong and Ho 2005; Orsolini et al. 2009; Mao et al. 2011a, b; He and Wang 2013; Gao et al. 2014; Zuo et al. 2015; Park and Ahn 2016; He et al. 2017; Qiao et al. 2018; Feng et al. 2018), but also has important effects on the climate of the South China Sea, tropical Indian Ocean precipitation, tropical atmospheric circulation and sea surface temperature (SST) in the western North Pacific (Mao et al. 2011a, b, c; Choi et al. 2012; Zuo et al. 2012; Hu et al. 2012; Gong et al. 2014). The 
mechanism of AO's impact on climate at different latitudes is more complicated. Some studies (Gong et al. 2000, 2003; Wu et al. 2004; Park et al. 2011; Li et al. 2014) show that the positive phase of the $\mathrm{AO}$ in winter is associated with the weak East Asian winter monsoon; the positive phase also creates warm conditions in East Asia by affecting the Siberian High, Rossby waves and polar jet. Concerning the areas at mid- and low latitudes, the AO may affect the temperature and precipitation in East Asia, especially in South China, as well as the westerly jet, wave trains, the Middle East jet (Qu et al. 2015; Zhang et al. 2008; Zuo et al. 2015) and the Pacific SST (Gong et al. 2011; Kim and Ahn 2012). Nevertheless, the mechanism of how the AO affects the climate at different latitudes is still controversial, and no consistent conclusion has yet been reached.

The AO is one of the key factors affecting temperature and precipitation anomalies in the tropical and subtropical regions. Gong and Wang (2003) found that more precipitation appears in China in association with the positive winter AO phase, which is consistent with the findings of Yang and $\mathrm{Li}$ (2008). During the positive phase of the AO, winter precipitation or snowfall events occur more frequently in China (Park et al. 2011). And the Middle East jet may have stronger influence on the temperature and precipitation in South China when the AO is positive (Wen et al. 2009). A significant positive correlation is also disclosed between the winter AO and precipitation in South China (Li and Wang 2013), which is consistent with the findings of Wen et al. (2009) and Matsuo and Heki (2012). The precipitation's increasing in Southeast China after the 1980s is closely related to the strengthened winter AO (Zhang et al. 2014). However, Choi et al. (2013) proposed negative correlation between the precipitation in North Korea and the AO in May. The correlation between the spring $\mathrm{AO}$ and summer precipitation abruptly turns from positive to negative in the late 1990s (Gao et al. 2014).

As for the South China regions, what is the main driver of precipitation in the area? Through the investigation of previous studies found that southwesterly wind flow (Zhao et al. 2007), monsoon (Zhou 2011), regional land thermal conditions (Wang et al. 2008), SST and so on (Tao and Chen 1987; Qi et al. 2008; Wang et al. 2000, 2001; Wu et al. 2003; Feng and Li 2011; Chen et al. 2014) play an important role in modulating precipitation over South China and its surrounding areas. AO might affect the precipitation at lower latitudes through different mechanisms. The possible pathways in which the AO affects the climate include the following aspects. Firstly, the AO may indirectly affect the winter climate through the Siberian High. Winter climate change caused by the AO is associated with the Siberian High (Gong et al. 2001). Secondly, the AO may directly affect the climate. Wu and Wang (2002) indicated that the winter AO may directly affect climate anomalies in East
Asia. The AO, East Asian winter monsoon, quasi-stationary planetary waves and the Middle East jet also have combined influence. AO may affect the East Asian climate via quasistationary planetary waves (Chen and Kang 2006). Zuo et al. (2015) showed that the anomalous relationship between the $\mathrm{AO}$ and temperature in South China is greatly dependent on the Middle East jet. And the strengthened relationship between the East Asian winter monsoon and winter $\mathrm{AO}$ after the 1980s may be attributed to the East Asian jet stream (Li et al. 2014). Moreover, the AO and SST may interact each other. The combined effect of the AO and North Pacific SST are presented on the East Asian temperature (Kim et al. 2012). During years characterized by positive-phase AO and El Nino or negative-phase AO and La Niña, the temperature anomalies in North China are exacerbated (Chen et al. 2017). In addition, the Indian Ocean Dipole (IOD) associated with atmospheric circulation first affects the East Asian summer monsoon and then affects the climate at low latitudes, such as the South China Sea (Li and Mu 2011).

A growing number of studies indicate that $\mathrm{AO}$ is a key factor influencing climate anomalies at lower latitudes, but the pathway by which it affects the climate is still contentious. Moreover, few studies have examined the potential influence of the $\mathrm{AO}$ on precipitation at the intraseasonal scale. In this study, we found that the October AO and November AO are in reverse-phase relationship with precipitation over the South China Sea and its surrounding areas (SCSA, $0^{\circ}-26^{\circ} \mathrm{N}, 86^{\circ}-126^{\circ} \mathrm{E}$ ). We also strove to understand and clarity the mechanisms by which the October AO and November AO affect the precipitation over the SCSA. This study aims to provide clarity of these mechanisms and increase our knowledge of how they operate.

We organize the present paper as follows. In Sect. 2, the reanalysis datasets, model datasets, and methods are described. Section 3 presents the statistical relationship between the October/November AO and the precipitation over the SCSA. In Sect. 4, the possible physical explanation for October/November AO-SCSA precipitation linkage and their reproducibility in models' simulation are discussed. Finally, summary and discussion are given in Sect. 5.

\section{Data and methodology}

The atmospheric datasets used in this study are composed of reanalysis data from the National Centers for Environmental Prediction and National Center for Atmospheric Research (NCEP) (Kalnay et al. 1996) with a spatial resolution of $2.5^{\circ} \times 2.5^{\circ}$. The variables include the sea level pressure (SLP), zonal and meridional winds at $850 \mathrm{hPa}$ (UV850) and $500 \mathrm{hPa}$ (UV500), geopotential height at $500 \mathrm{hPa}$ (GPH500), zonal wind at $200 \mathrm{hPa}$ (U200), specific humidity, latent and sensible heat fluxes, total cloud cover, 
$10 \mathrm{~m}$ winds and vertical velocity at each pressure level. The monthly precipitation data are from the Global Precipitation Climatology Project (GPCP v2.3) (Adler et al. 2003 ) with a resolution of $2.5^{\circ} \times 2.5^{\circ}$. Monthly sea surface temperature (SST) data is from the Hadley Centre Sea Ice and Sea Surface Temperature (HadISST) datasets with a spatial resolution of $1^{\circ} \times 1^{\circ}$ (Rayner 2003).

Monthly mean AO index is obtained from the Climate Prediction Center (CPC) of the US National Oceanic and Atmospheric Administration (NOAA). In research on the aforementioned mechanism, the signals of El Niño/ Southern Oscillation (ENSO) and the Indian Ocean Dipole (IOD) need to be linearly removed. Thus, linear regressions of the variables with ENSO and the IOD are conducted. Then, the residuals are regarded as variations that are statistically independent of ENSO and IOD. Here, the ENSO signal is measured by the Nino 3.4 index, which is the average SST anomaly in the region bounded by $5^{\circ} \mathrm{S}$ to $5^{\circ} \mathrm{N}$, from $170^{\circ} \mathrm{W}$ to $120^{\circ} \mathrm{W}$. The intensity of IOD is represented by anomalous SST gradient between the western equatorial Indian Ocean $\left(50^{\circ}-70^{\circ} \mathrm{E}\right.$ and $\left.10^{\circ} \mathrm{S}-10^{\circ} \mathrm{N}\right)$ and the south eastern equatorial Indian Ocean $\left(90^{\circ}-110^{\circ} \mathrm{E}\right.$ and $10^{\circ} \mathrm{S}-0^{\circ}$ ) (Saji et al. 1999). All monthly averaged variables are selected for the analyses period of 1979-2014. Furthermore, the latitudes and longitudes of the South China Sea and surrounding areas (SCSA) is at $0-26^{\circ} \mathrm{N}, 86-126^{\circ} \mathrm{E}$. The results are robust and insensitive to small changes for the definition of this area.

The moisture budget deals with the mass conservation of water substance in atmospheric column, and it is widely used to examine precipitation distributions and changes (Chou and Lan 2012). The moisture budget analysis defines the mass conservation of water substance in an atmospheric column as Eq. (1).

$\overline{\mathrm{P}}+\overline{\left\langle\partial_{\mathrm{x}}(\mathrm{uq})\right\rangle}+\overline{\left\langle\partial_{\mathrm{y}}(\mathrm{vq})\right\rangle}+\overline{\left\langle\partial_{\mathrm{p}}(\omega \mathrm{q})\right\rangle}+\operatorname{Res}=\overline{\mathrm{E}}$

Here $\mathrm{P}$ is precipitation, $\mathrm{q}$ is specific humidity, $\mathrm{u} / \mathrm{v}$ is zonal (meridional) wind, $\omega$ is vertical pressure-velocity, Res is the residual term and $\mathrm{E}$ is evaporation into atmosphere, respectively. Evaporation data is from the Japanese 55-year Reanalysis (JRA-55) (Ebita et al. 2011; Kobayashi et al. 2015). In this study, $\langle X>$ indicates a mass-weighted vertical integral and $\bar{X}$ denotes a temporal average. Total moisture flux convergence is decomposed into terms of circulation convergence and moisture advection. Thus, the horizontal advection in Eq. (1) can be further decomposed into stationary and transient terms as follows:

$\mathrm{X}=\overline{\mathrm{X}}+\mathrm{X}^{\prime}=\overline{[\mathrm{X}]}+\overline{\mathrm{X}}^{*}+\mathrm{X}^{\prime}$

In Eq. (2), $[X]$ and $X^{*}$ are climatological zonal mean and stationary eddy, respectively, and $\mathrm{X}^{\prime}$ is transient variation. Then we can distinguish the contributions from different time and spatial scales to climatology (1979-2014). More details can be found from the literatures (Yao et al. 2017; Chen et al. 2018; Lin et al. 2019).

Coupled Model Intercomparison Project phase 6 (CMIP6) (Eyring et al. 2016; Simpkins 2017; Zhao et al. 2018) data are archived by the Program for Climate Model Diagnosis and Intercomparison (PCMDI) (https://esgf-node. 1lnl.gov/projects/cmip6/). Among all the CMIP iterations since the program was first developed, CMIP6 has the largest number of modes, the most complete scientific experiments, and the largest amount of simulation data (Zhou et al. 2016; Haarsma et al. 2016; Griffies et al. 2016; Kageyama et al. 2018). More than 20 modeling groups are performing CMIP6 simulations using more than 50 models (Eyring et al. 2016; Gillett et al. 2016; Boer et al. 2016; Zhou et al. 2019). In this study, the historical experiments' outputs of 11 models (Table 1) are employed. In addition, only one ensemble member from each model is chosen for the present research.

\section{Reversal of the October and November AO on the precipitation over the SCSA}

The spatial distributions of the high-, middle- and low-level climate backgrounds over the SCSA in October and November are examined (Fig. 1). More precipitation appears in the southern area in October (Fig. 1a) than that in November (Fig. 1b). In addition, the northerly winds at $850 \mathrm{hPa}$ over the South China Sea and Thailand in November are stronger than those in October, which may bring dry airflows from high latitudes. In the Bay of Bengal, the southerly winds are more obvious in October than in November, which may transport moisture from the tropical ocean. Furthermore, the East Asian westerly jet system in the upper troposphere is an important circulation system at high altitudes. In November, the westerly jet (Fig. 1d) is significantly stronger than that in October (Fig. 1c), and the axis of the East Asian westerly jet is located more southward. The previous study (Mao et al. 2007) showed that AO may impact the East Asian westerly jet system and winter precipitation in South China. Qu et al. (2015) revealed that AO has significant impacts on spring precipitation in South China. The following sections will discuss the impacts of the October and November AO (Oct/ Nov AO) on the precipitation over the SCSA.

The spatial distributions and time series of the correlation coefficients between the precipitation over the SCSA $\left(0-26^{\circ} \mathrm{N}, 86-126^{\circ} \mathrm{E}\right)$ and the Oct/Nov AO during 1979-2014 are shown in Fig. 2. The results show large differences between October and November. In October, significant positive correlation between the precipitation and AO exists in most of the SCSA (Fig. 2a), while there is significant negative correlation between the precipitation and $\mathrm{AO}$ in 
Table 1 Details of the 11 CMIP6 climate models used in this study

\begin{tabular}{lll}
\hline Model & Institute, country & $\begin{array}{c}\text { Horizontal } \\
\text { Resolution } \\
(\text { lat } \times \text { lon })\end{array}$ \\
\hline BCC-CSM2-MR & Beijing Climate Center, China Meteorological Administration China & $1.1^{\circ} \times 1.1^{\circ}$ \\
BCC-ESM1 & Beijing Climate Center, China & $2.8^{\circ} \times 2.8^{\circ}$ \\
CAMS-CSM1-0 & Chinese Academy of Meteorological Sciences, China & $1.1^{\circ} \times 1.1^{\circ}$ \\
CanESM5 & Canadian Centre for Climate Modelling and Analysis, Environment and Climate Change Canada, Canada & $2.8^{\circ} \times 2.8^{\circ}$ \\
CESM2 & National Center for Atmospheric Research, Climate and Global Dynamics Laboratory, USA & $0.94^{\circ} \times 1.25^{\circ}$ \\
CESM2-WACCM & National Center for Atmospheric Research, Climate and Global Dynamics Laboratory, USA & $0.94^{\circ} \times 1.25^{\circ}$ \\
GISS-E2-1-G & NASA Goddard Institute for Space Studies, USA & $2.0^{\circ} \times 2.5^{\circ}$ \\
GISS-E2-1-H & NASA Goddard Institute for Space Studies, USA & $2.0^{\circ} \times 2.5^{\circ}$ \\
MIROC6 & The University of Tokyo, National Institute for Environmental Studies, and Japan Agency for Marine- & $1.4^{\circ} \times 1.4^{\circ}$ \\
SAM0-UNICON & Earth Science and Technology, Japan & $0.94^{\circ} \times 1.25^{\circ}$ \\
MRI-ESM2-0 & Metional Seoul University, Korea & $1.1^{\circ} \times 1.1^{\circ}$ \\
\hline
\end{tabular}

November (Fig. 2b). It should be noted that the significant positive correlation areas are distributed in Thailand, Myanmar and Vietnam in October. However, the negative correlation is over Bay of Bengal, Myanmar and South China Sea in November. The linear correlation coefficients between AO and precipitation index in the SCSA are further calculated. And the precipitation index is calculated on the basis of area average in $\operatorname{SCSA}\left(0^{\circ}-26^{\circ} \mathrm{N}, 86^{\circ}-126^{\circ} \mathrm{E}\right)$. It is found that the AO is significantly correlated with the October precipitation with a correlation coefficient of 0.44 (Fig. 2c), which is statistically significant at the $95 \%$ confidence level according to a two-tailed Student's t-test. Of all 17 years of the positive-phase AO, 11 years (accounting for 64.7\%) exhibit positive precipitation anomalies in October. Of all 19 years of the negative-phase $\mathrm{AO}, 10$ years (accounting for 52.6\%) display negative precipitation anomalies in October. The mutual influences and changes between the AO and October precipitation are strongly related to a frequent in-phase relationship during the period of 1979-2014 (Fig. 2c). Out of the 36 years, there are 21 years when the October AO and precipitation are in phase, accounting for approximately $58.3 \%$ of all events. In contrast, significant negative correlation appear between the $\mathrm{AO}$ and precipitation in November (Fig. 2d). The out-of-phase variations are revealed between the November AO and precipitation with a correlation coefficient of -0.31 (at the $90 \%$ confidence level). Moreover, an out-of-phase relationship between the November AO and precipitation is found in 24 out of 36 years, which accounts for approximately $66.7 \%$ of all events.

The precipitation anomalies are closely related to both the water vapor transported at the lower-level of the troposphere as well as the vertical ascending motion. Hence, we compute the regression coefficients between $\mathrm{AO}$ and the mass-weighted average specific humidity over the lower troposphere (1000-500 hPa) as well as vertical velocity in
October and November, respectively (Fig. 3). The specific humidity anomalies extend throughout the lower troposphere. In October, the specific humidity anomalies show obvious positive anomalies from 1000 to $500 \mathrm{hPa}$ in most of the SCSA (Fig. 3a). Along with the winds at lower level, the southerly winds transport water vapor from the tropical ocean, which provide favorable conditions for precipitation in the study region (Fig. 5a, b). In contrast, significant negative specific humidity anomalies are observed in November (Fig. 3b). It can be found that the meteorological variable distributions are similar, and the precipitation increases significantly in the area where the specific humidity increases dramatically in October (Figs. 2a, b, 3a, b). Correspondingly, the precipitation in November decreases in these areas where the specific humidity decreases noticeably. The precipitation-related vertical velocity is also examined in height-latitude sections. Figure 3c, d present the zonalmean zonal and meridional winds between $86^{\circ} \mathrm{E}$ and $126^{\circ} \mathrm{E}$ in October and November, respectively. Between $10^{\circ} \mathrm{N}$ and $30^{\circ} \mathrm{N}$, significant vertical ascending motion appears from the ground to $150 \mathrm{hPa}$, which may create possible dynamic conditions for precipitation's increasing over the SCSA in October. Compared with October (Fig. 3c), there is significant sinking motion in November between $10^{\circ} \mathrm{N}$ and $20^{\circ} \mathrm{N}$ (Fig. 3d), which may be related to precipitation's decreasing throughout the study area.

Moisture budget analysis are widely used to examine precipitation distributions and changes (Chou and Lan 2012), we also examine the moisture budget on AO in October and November using diagnostics for precipitation changes. Figure 4 shows the moisture budget diagnosis (Eq. 1) results over SCSA. In October, the precipitation's increasing is mainly contributed by zonal convergence $\left(-\partial_{\mathrm{x}}(\overline{\mathrm{uq}})\right)$ partly offset by local evaporation and meridional moisture flux divergence $\left(-\partial_{\mathrm{y}}(\overline{\mathrm{vq}})\right)$ over SCSA (Fig. 4a, red bars). One 
(a) Oct

Pre \& UV850

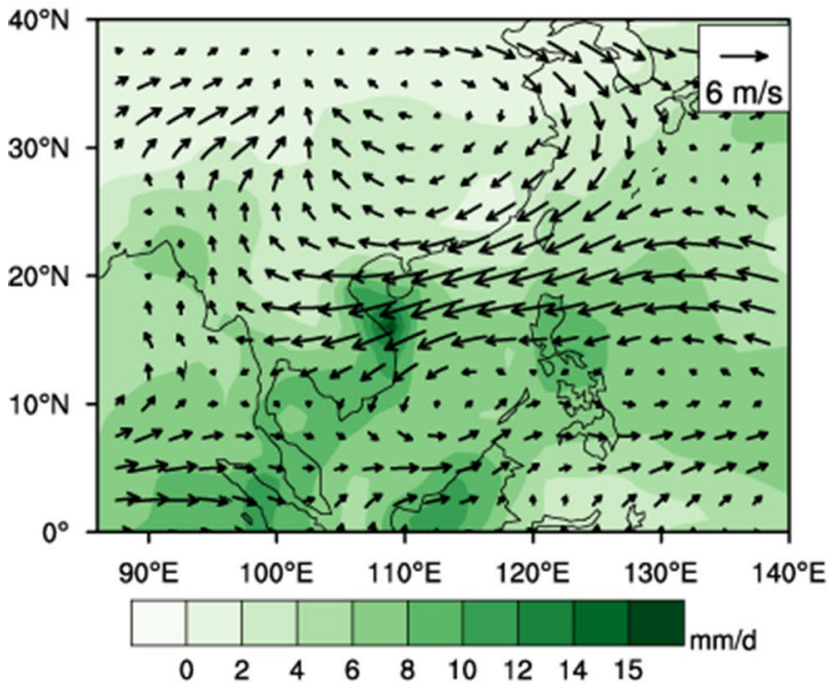

(c) Oct

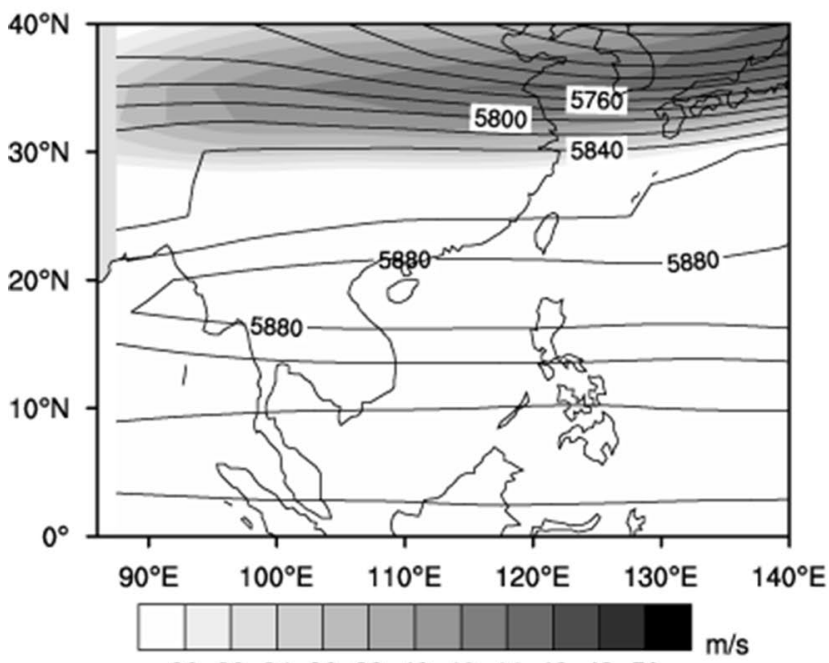

$30 \quad 32 \quad 3436 \quad 3840 \quad 4244 \quad 46 \quad 4850$ (b) Nov

Pre \& UV850

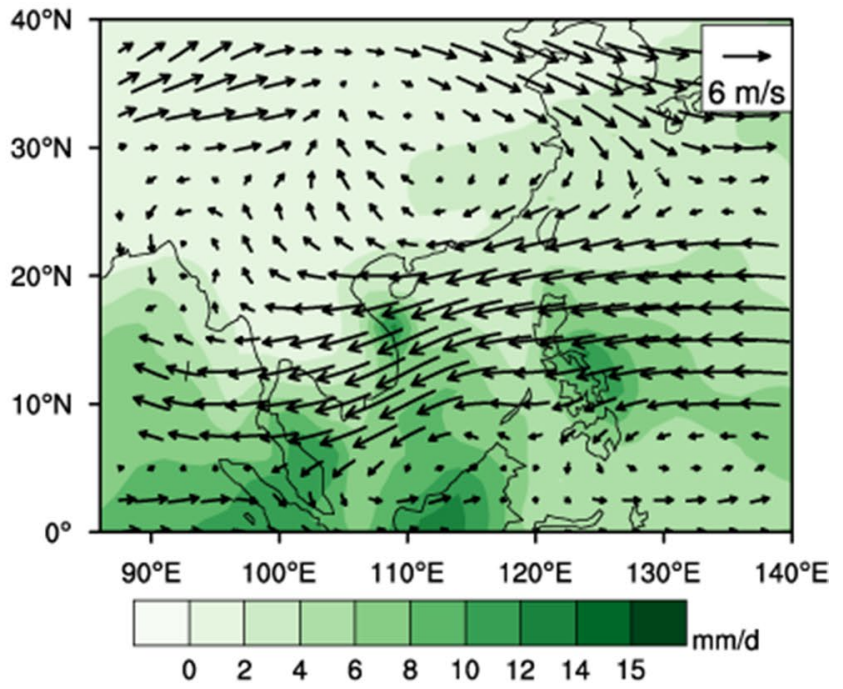

(d) Nov

U200 \& GPH500

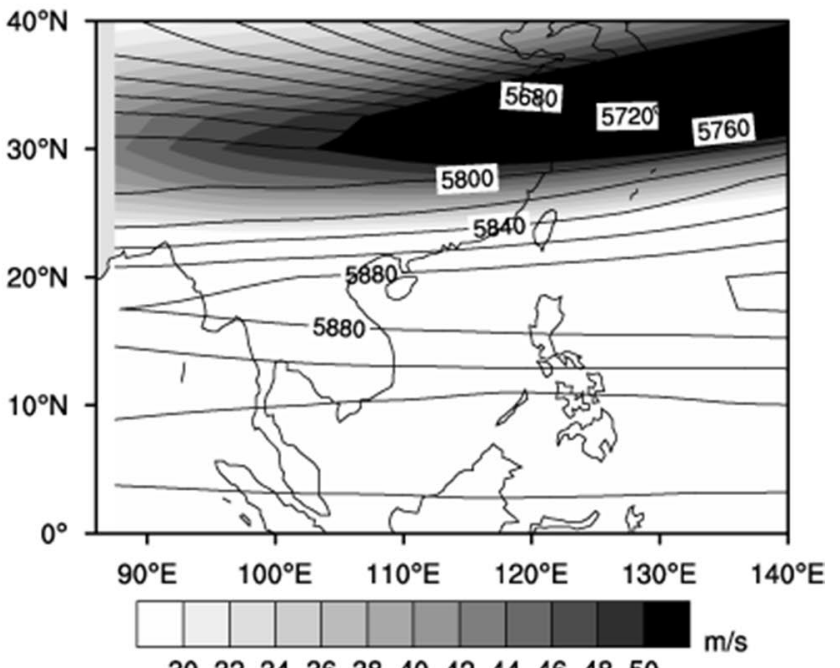

$30 \quad 32 \quad 34 \quad 3638 \quad 40 \quad 4244 \quad 46 \quad 4850$

Fig. 1 The climatology of the a precipitation (shading, units: mm/day) and $850 \mathrm{hPa}$ wind (vectors, units: $\mathrm{m} / \mathrm{s}$ ) and c $500 \mathrm{hPa}$ geopotential height (shading, units: gpm) and $200 \mathrm{hPa}$ zonal wind (contours, units: m/s) in October for 1979-2014. b and d are the same as a and c, but in November

contributors to the zonal moisture flux convergence is the stationary eddy zonal moisture transported via meridional flow convergence $\left(-\overline{\left[\mathrm{q}^{*}\right]} \partial_{\mathrm{y}} \overline{\mathrm{u}}^{*}\right)$, and the other is the zonalmean moisture transported via stationary eddy zonal flow divergence $\left(-\overline{[\mathrm{q}]} \partial_{\mathrm{y}} \overline{\mathrm{u}}^{*}\right)$. The decrease of precipitation in November is contributed by zonal $\left(-\partial_{\mathrm{x}}(\overline{\mathrm{uq}})\right)$ and meridional moisture flux divergence $\left(-\partial_{\mathrm{y}}(\overline{\mathrm{vq}})\right)$ over SCSA (Fig. 4a, blue bars), although it's not statistically significant. The vertical moisture transported in October and November is not obvious. The spatial patterns of moisture budget components are shown in Fig. 4b-g. In most of SCSA, zonal moisture flux is positive in October (Fig. 4b). On the contrary, zonal moisture flux transported in November is negative in Thailand and the southern of South China Sea, while it's positive in the northern of South China Sea (Fig. 4c). In October, the meridional moisture flux component is negative over Myanmar, south of the Bay of Bengal and south of South China Sea, while positive over Thailand and Hainan and western Qinghai (Fig. 4d). Due to the canceling effect of the positive and negative components over SCSA, the vertical moisture flux term as a whole contributes a little to the precipitation both in October and November (Fig. 4f-g).

In general, the increase of precipitation in October mainly contributed by zonal moisture flux convergence $\left(-\partial_{\mathrm{x}}(\overline{\mathrm{uq}})\right)$, 
(a) Oct

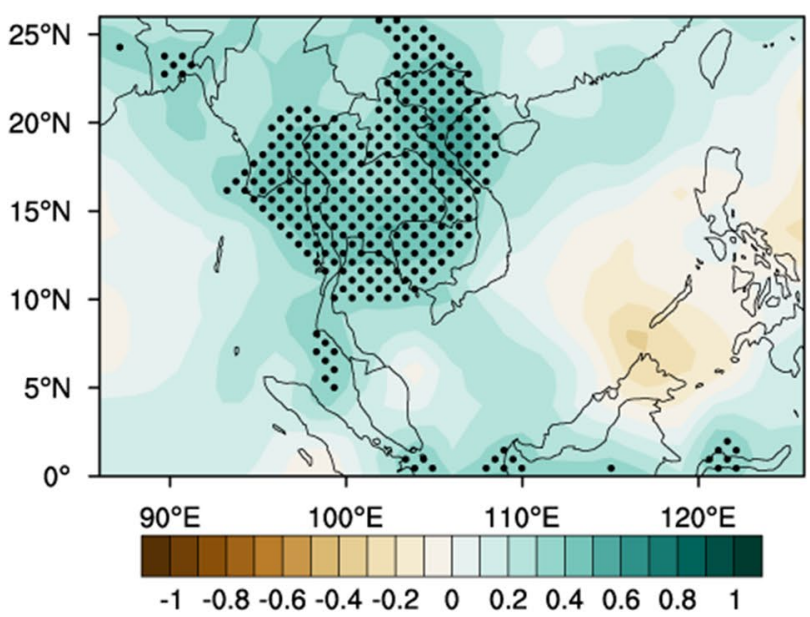

(c) Oct

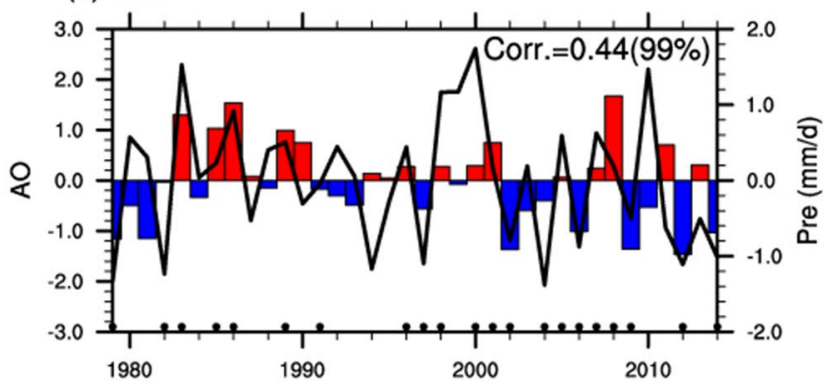

Fig. 2 a Spatial distributions of the correlation coefficients between the $\mathrm{AO}$ index and October precipitation; dotted regions indicate significance at the $95 \%$ confidence level using a two-tailed Student's t-test. c Normalized and detrended time series of the October AO index (bars) and precipitation (line) during 1979-2014; the dots in the bottom panel indicate the in-phase/out-of-phase years in October/

and its decrease in November mainly contributed by zonal divergence.

\section{Possible mechanisms}

\subsection{AO-related atmospheric circulation anomalies}

To better understand the influences of the Oct/Nov AO on the precipitation over the SCSA, it is crucial to clarify the relationships between the atmospheric circulation anomalies and the AO index. For this purpose, the regression coefficient distributions of the AO-related circulation anomalies in October and November during 1979-2014 are presented. Figure 5 shows the regression coefficients between the meteorological variables (including SLP, winds at $850 \mathrm{hPa}$ and $500 \mathrm{hPa}$, geopotential height at $500 \mathrm{hPa}$ and zonal winds at $200 \mathrm{hPa}$ ) and the AO index after removing the ENSO and IOD signals.

\section{(b) Nov}

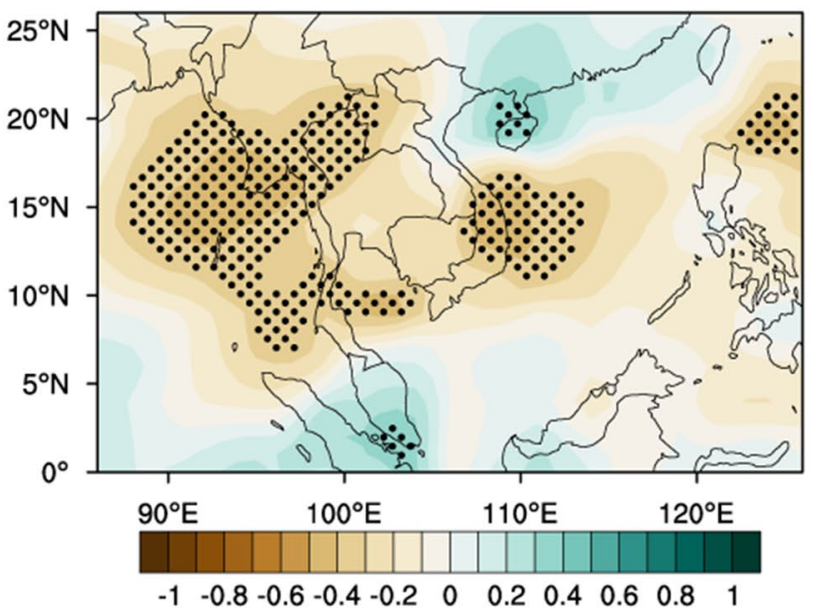

(d) Nov

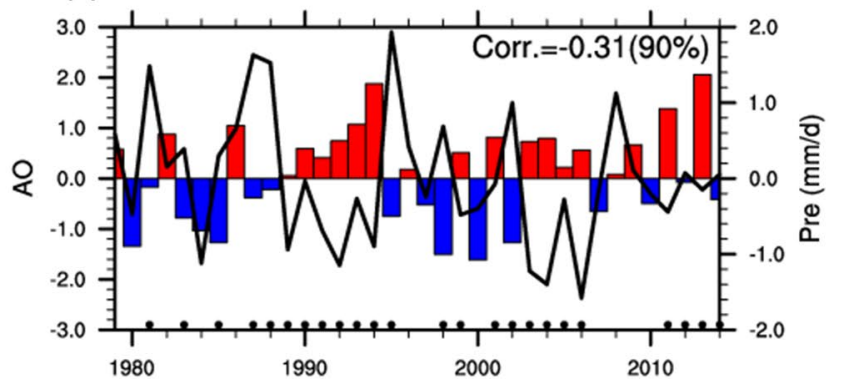

November between the AO and precipitation. The correlation coefficients between the October/November $\mathrm{AO}$ and precipitation are given in the top right-hand corner, which are significant at the $99 \% / 90 \%$ confidence level using a two-tailed Student's t-test. b and $\mathbf{d}$ are the same as $\mathbf{a}$ and $\mathbf{c}$, but for the November precipitation

Northward/southward flow to the South China Sea gives rise to high/low precipitation there (Fig. 5a, b). It seems that the source of moisture mainly comes from the Bay of Bengal (southwesterly wind) in October and the Pacific Ocean (northeasterly wind) becomes mainly source of moisture in November. In October, the change of the Siberian High is not obvious, while the Aleutian Low is significantly weaker, and a strong anticyclone appears over the North Pacific. In November (Fig. 5d), a dipole-like pattern is observed over the North Pacific (i.e., a pair of anomalous circulations occupies the North Pacific, representing anticyclonic circulation anomalies over the mid- and high-latitudes and cyclonic circulation anomalies at lower latitudes), and this dipolelike pattern becomes distinct in the upper troposphere. In the field of the $500 \mathrm{hPa}$ geopotential height, significant positive anomalies are located over Baikal and East Asia, indicating the possibility that the East Asian Trough weakens in October. Compared with that in November (Fig. 5e), the East Asian Trough anomaly is not significant. In the 
(a) Oct $\operatorname{Reg}(\mathrm{AO}, \mathrm{SH})$

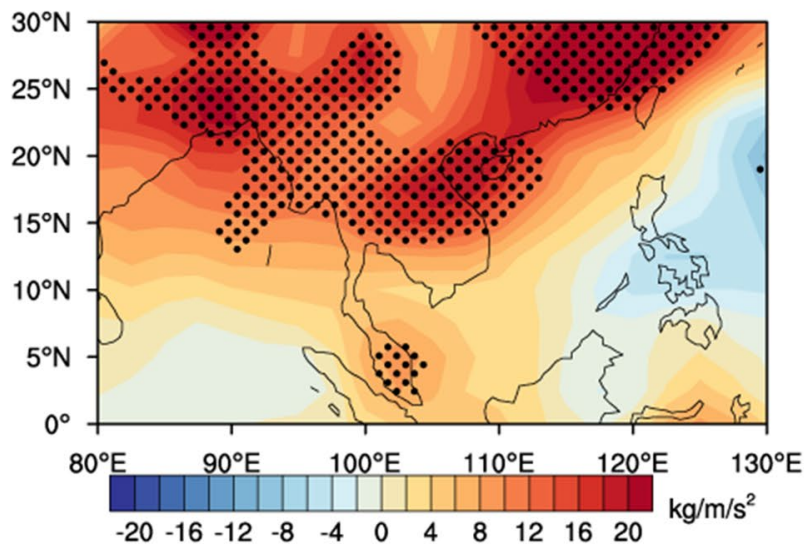

(c) Oct
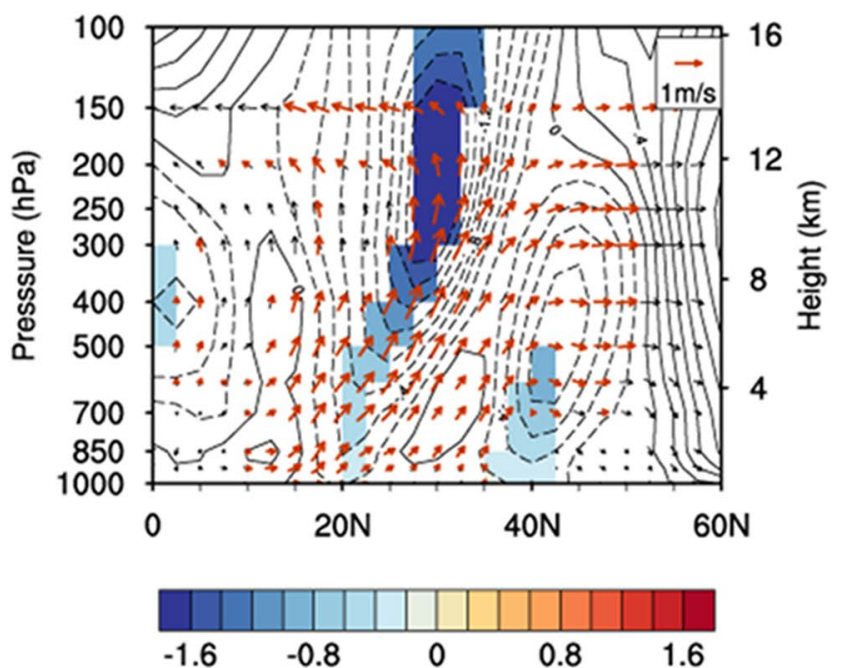

Fig. 3 Regression coefficients of the following variables in October, a mass-weighted average specific humidity over the lower troposphere $\left(1000-500 \mathrm{hPa}\right.$, units: $\left.\mathrm{kgm}^{-1} \mathrm{~s}^{-2}\right)$. c Zonal-mean zonal wind $(\mathrm{u})$, meridional wind $(\mathrm{v})$, and vertical motion (w) over the SCSA $\left(86^{\circ} \mathrm{E}-126^{\circ} \mathrm{E}\right)$ superposed onto the AO index; the contour lines represent $\mathrm{u}(\mathrm{m} / \mathrm{s})$, and the vectors represent $\mathrm{v}(\mathrm{m} / \mathrm{s})$ and $\mathrm{w}\left(10^{-4} \mathrm{hPa} / \mathrm{s}\right)$. Dotted regions in $\mathbf{a}$ and $\mathbf{b}$ indicate that the coefficients are statistically

$200 \mathrm{hPa}$ zonal wind field (Fig. 5c, f), significant negative anomalies occur in the area where the East Asian jet core is located (He and Wang 2013), and the zonal winds to the north and south of the jet become relatively strong. Moreover, a "positive-negative-positive-negative" distribution of the zonal wind in the upper-level troposphere moving from West Europe to the Arabian Sea is observed both in October and November. The notable difference is observed that the $200 \mathrm{hPa}$ zonal wind anomalies dominating the Arabian Sea region in October is no longer significant in November. Mao et al. $(2011 \mathrm{a}, \mathrm{b}, \mathrm{c})$ revealed that the AO might affect the East Asian westerly jet.

We also investigate the circulations favoring precipitation in October and November (figure is not given), to (b) Nov $\operatorname{Reg}(\mathrm{AO}, \mathrm{SH})$

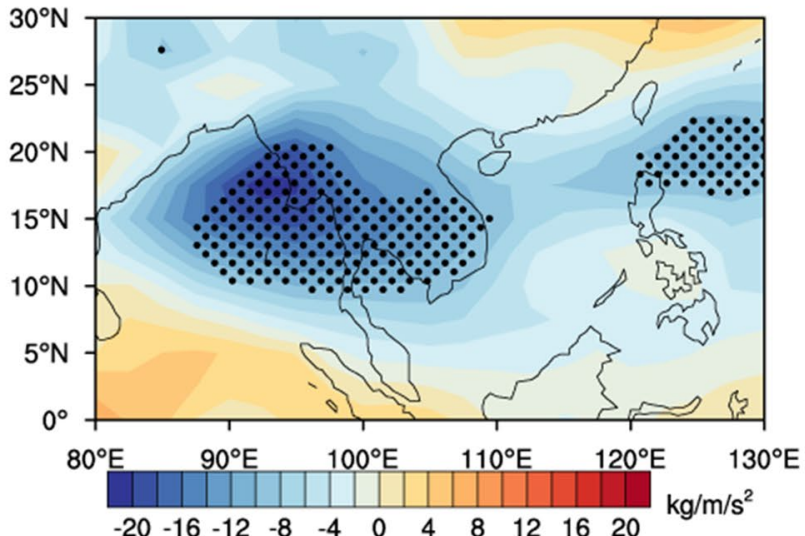

(d) Nov

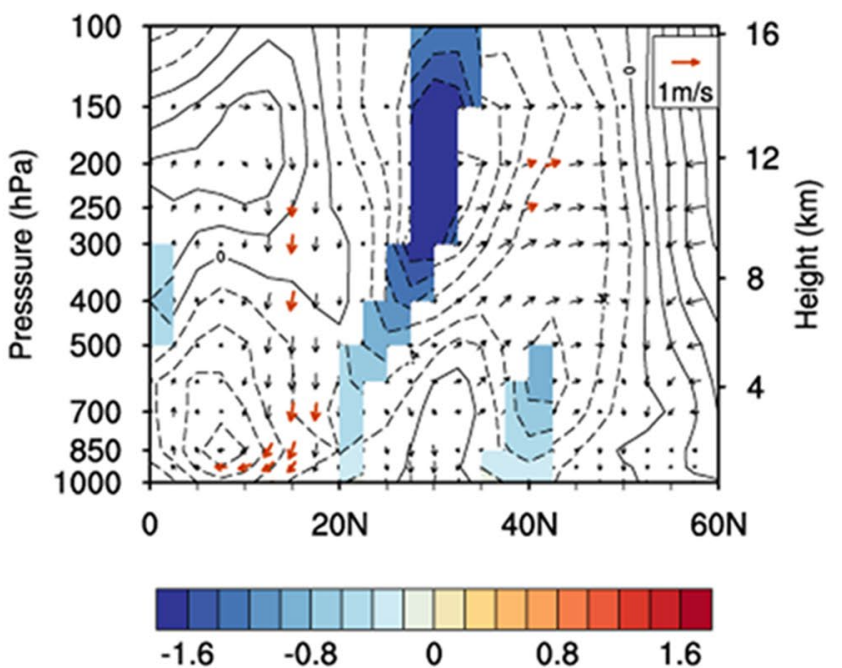

significant at the $95 \%$ confidence level using a two-tailed Student's $\mathrm{t}$-test. Red and blue contours in $\mathbf{c}$ and $\mathbf{d}$ indicate zonal wind anomalies significant at the $90 \%$ confidence level. Red arrows indicate that components of the wind anomalies are statistically significant at the $90 \%$ confidence level. $\mathbf{b}$ and $\mathbf{d}$ are the same as $\mathbf{a}$ and $\mathbf{c}$, but in November

confirm the atmospheric circulation features with regard to the AO-SCSA precipitation relationships. The majority of the spatial pattern of the precipitation-related atmosphere circulation resembles the AO-related pattern in October. Furthermore, there is a cyclonic circulation anomaly in the northern North Pacific and an anticyclonic circulation at lower latitudes in November, which is different from the AO-related pattern. Next, the wind anomalies in the upper troposphere associated with the Oct/Nov AO are studied. After removing the ENSO and IOD signals, the change in the $200 \mathrm{hPa}$ wind velocity corresponding to one unit change of the AO index is calculated at each grid, and the result is shown in Fig. 6. The most prominent feature is the alternating anticyclone and cyclone pattern 
Fig. 4 Moisture budget analysis of rainfall changes (units: $\mathrm{mm} /$ day) under the $\mathrm{AO}$ influence in October and November during 1979-2014. a Regression coefficients of moisture budget analysis on $\mathrm{AO}$ (dots denote anomalies significant at $95 \%$ confidence level) in October (red color bars) and November (blue color bars). Rainfall change is balanced by the changes of evaporation, zonal, meridional and vertical moisture flux components, and the residual (left to the dashed line) and major processes contributing to moisture flux convergence (right to the dashed line). b, d, f Spatial patterns of zonal, meridional and vertical component in October, respectively. $\mathbf{c}, \mathbf{e}, \mathbf{g}$ are same as $\mathbf{b}, \mathbf{d}, \mathbf{f}$ but for November. Dotted regions indicate that the coefficient is significant at the 90\% confidence level using a two-tailed Student's t-test

(a) $\operatorname{Reg}$ ( $A O$ \& Moisture budget )

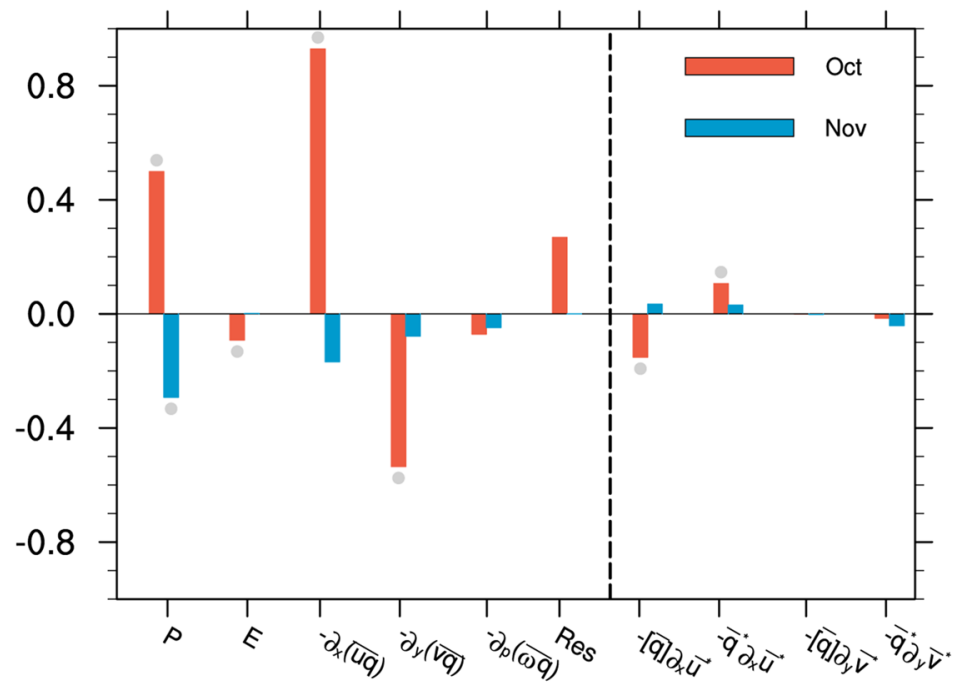

(b) Oct $\operatorname{Reg}\left(A O,-\partial_{x}(\overline{u q})\right)$

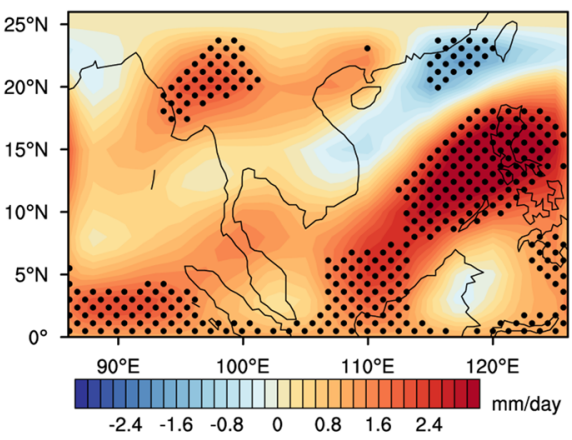

(d) Oct $\operatorname{Reg}\left(\mathrm{AO},-\partial_{\mathrm{y}}(\overline{\mathrm{vq}})\right)$

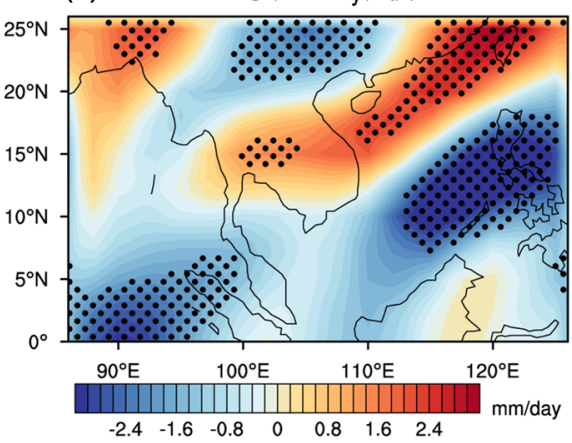

(f) Oct $\operatorname{Reg}\left(A O,-\partial_{p}(\overline{\omega q})\right)$

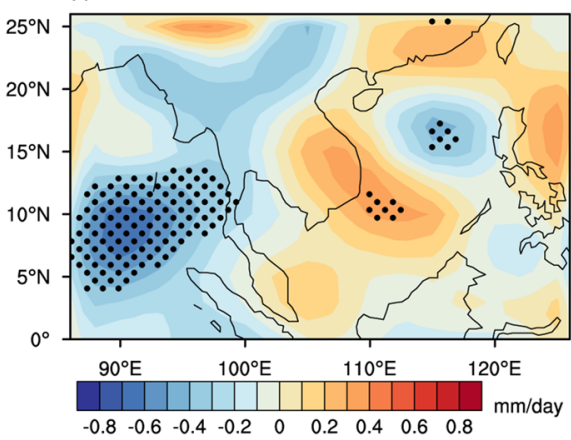

(c) Nov $\operatorname{Reg}\left(A O,-\partial_{x}(\overline{u q})\right)$

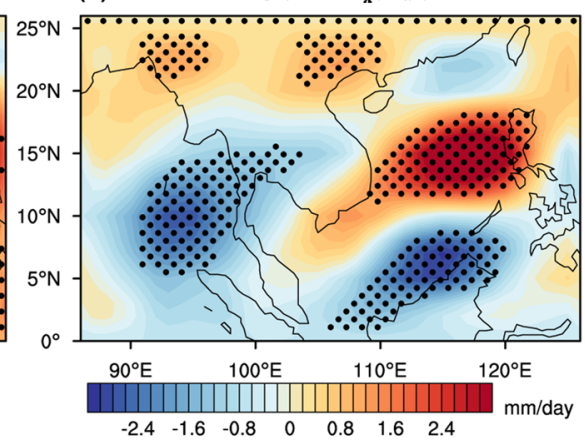

(e) Nov $\operatorname{Reg}\left(A O,-\partial_{y}(\overline{v q})\right)$

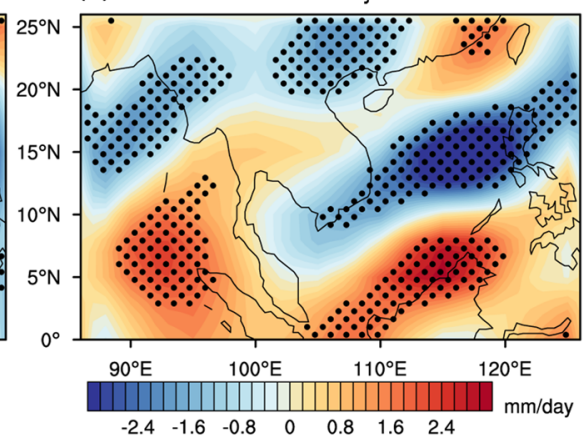

(g) Nov

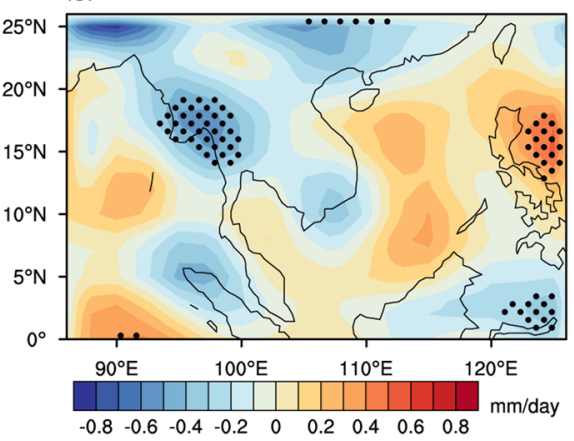


(a) Oct

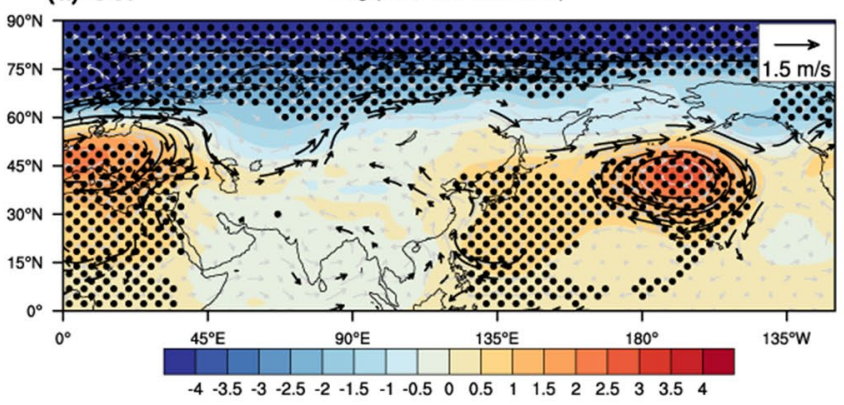

(b) Oct

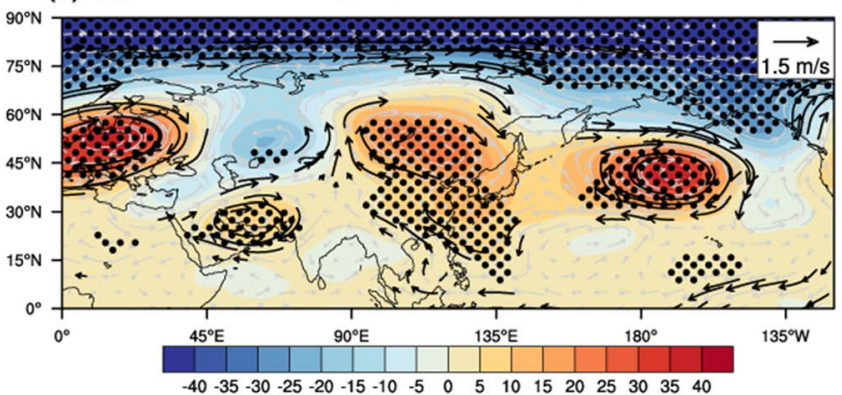

(c) Oct

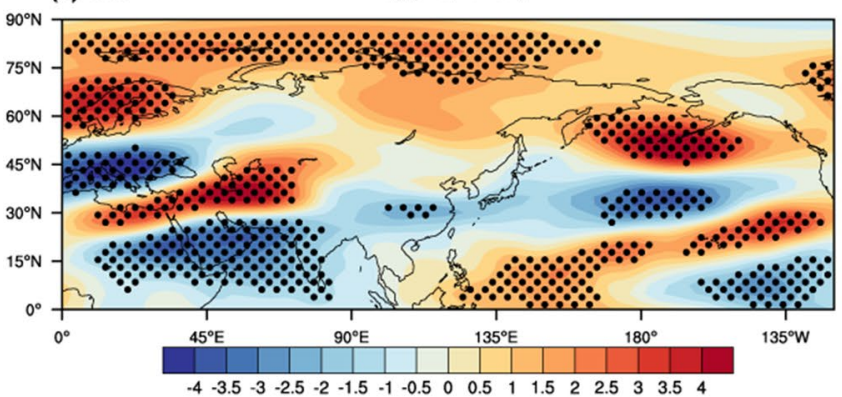

Fig. 5 Regression coefficients of the following variables with the AO index in October during 1979-2014: a wind at $850 \mathrm{hPa}$ (vectors, units: $\mathrm{m} / \mathrm{s}$ ) and SLP (shading, units: $\mathrm{hPa}$ ), b geopotential height (shading, units: gpm) and wind at $500 \mathrm{hPa}$ (vectors, units: $\mathrm{m} / \mathrm{s}$ ) and c zonal wind at $200 \mathrm{hPa}$ (units: $\mathrm{m} / \mathrm{s}$ ). d-f are the same as $\mathbf{a}-\mathbf{c}$, but in

in the east-west direction that clearly generated by two wave trains. One wave train is from North Europe propagating eastward through Siberia to the Sea of Japan along belts between $40^{\circ} \mathrm{N}$ and $65^{\circ} \mathrm{N}$, and this phenomenon is called the northern wave train. The other is from North Africa passing through the Arabian Sea and the Bay of Bengal and then to the South China Sea (Gong et al. 2014) between $0^{\circ} \mathrm{N}$ and $30^{\circ} \mathrm{N}$, which is called the southern wave train. Comparing Fig. 6a, b, it is found that the anticyclone over the Arabian Sea is extremely strong at the $200 \mathrm{hPa}$ wind field in October, while there are anomalous anticyclones and cyclones moving from North Africa through the Arabian Sea and the Bay of Bengal to the South China Sea in November. Meanwhile, the dipole-like pattern (d) Nov

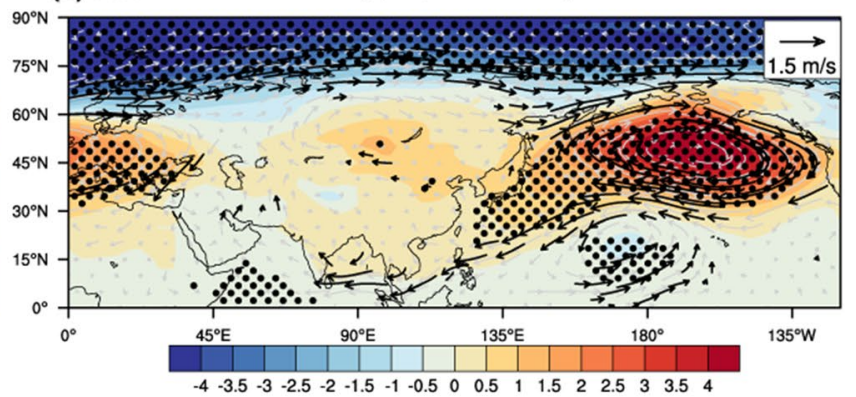

(e) Nov

$\operatorname{Reg}($ AO, GPH500 \& UV500)

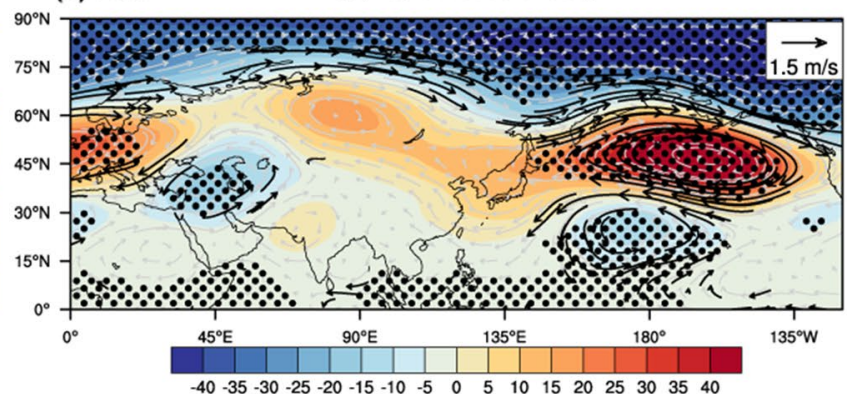

(f) Nov

$\operatorname{Reg}(\mathrm{AO}, \mathrm{U} 200$ )

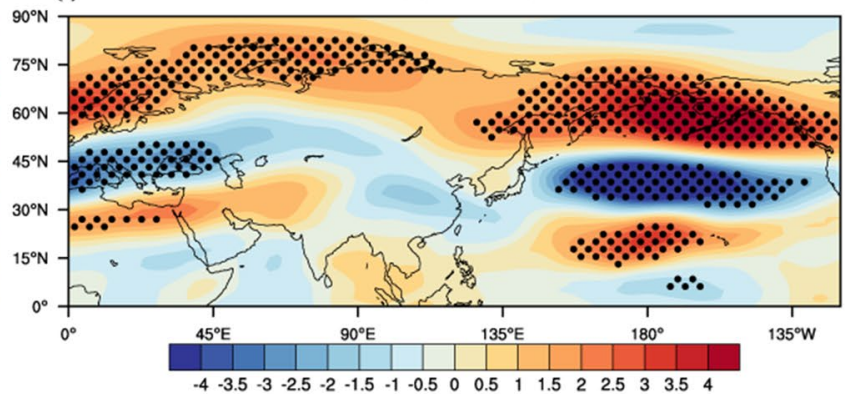

November. Dotted regions indicate that the coefficient is significant at the $95 \%$ confidence level using a two-tailed Student's t-test. Black and gray arrows indicate that both components of the wind anomalies are statistically significant and nonsignificant, respectively, at the $90 \%$ confidence level over the North Pacific in November moves eastward and becomes stronger than that in October.

Based on the analysis in this paper and the results of previous research, it can be concluded that both the dipole pattern and the southern wave train have an impact on the South China climate. In view of this, how these two phenomena affect the inverse relationships between the $\mathrm{AO}$ and precipitation in October and November over the SCSA is investigated. The Northern Pacific dipole pattern and southern wave train are described quantitatively; accordingly, the North Pacific dipole index (DCA) and southern wave train index (SWT) are defined. The characteristics of the largescale atmospheric circulation corresponding to the cyclones and anticyclones in the North Pacific region are described by 
Fig. 6 Regression coefficients between the $200 \mathrm{hPa}$ wind and the $\mathrm{AO}$ index in $\mathbf{a}$ October, $\mathbf{b}$ November during 1979-2014. The shaded areas represent the winds that are statistically significant at the $90 \%$ confidence level. The ENSO and IOD signals are removed (a) Oct

$\operatorname{Reg}(\mathrm{AO}, \mathrm{UV} 200)$

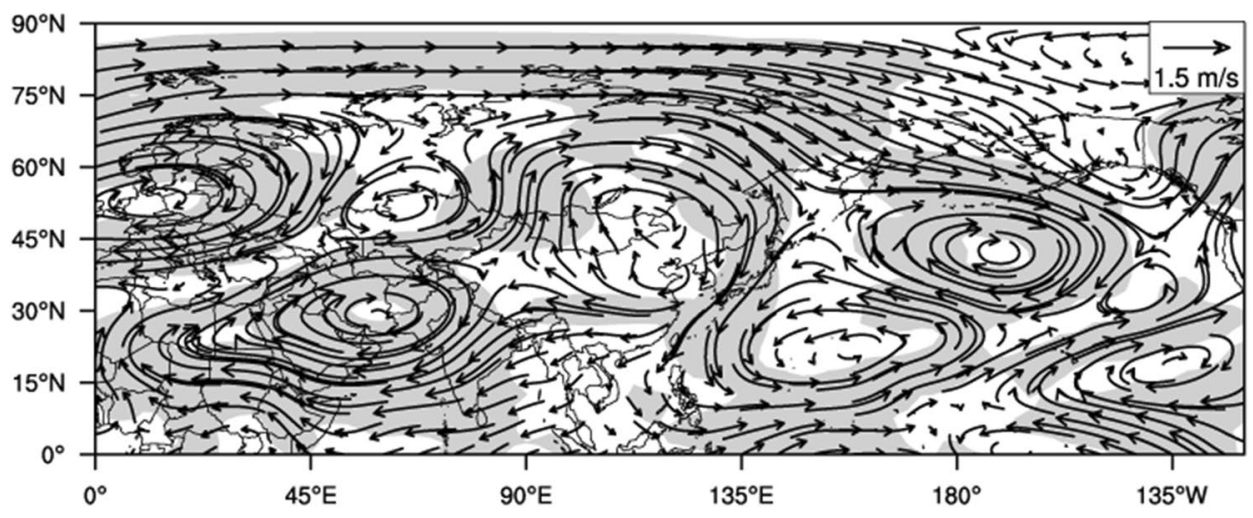

(b) Nov

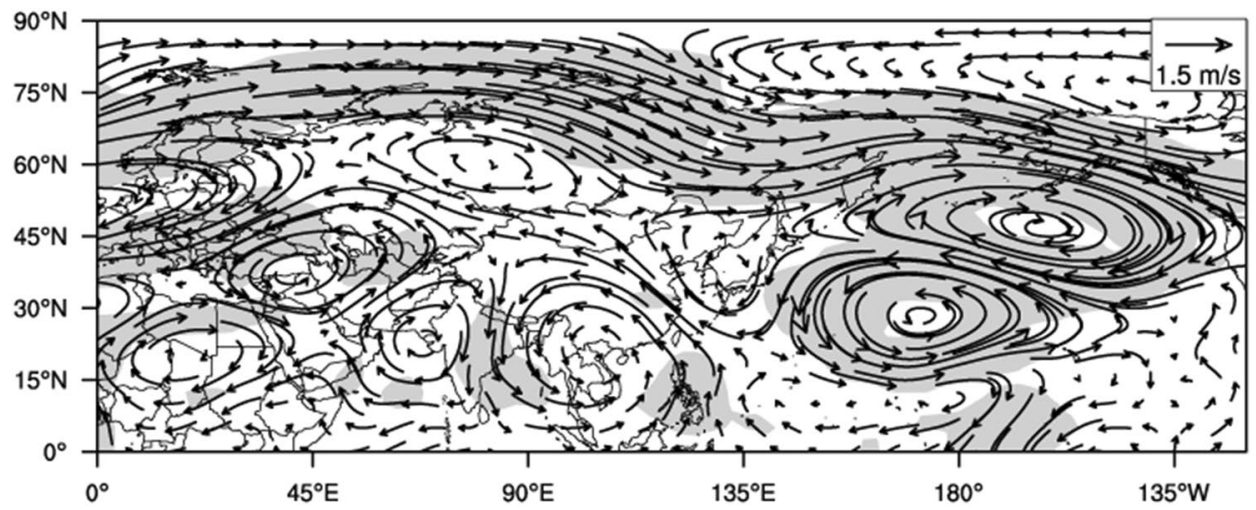

using the differences in the normalized $200 \mathrm{hPa}$ geopotential height fields. In Fig. 6a, the anticyclone center in October lies within approximately $40^{\circ} \mathrm{N}-47.5^{\circ} \mathrm{N}, 177.5^{\circ} \mathrm{E}-165^{\circ} \mathrm{W}$, while the anomalous cyclone center is located within $20^{\circ} \mathrm{N}-27.5^{\circ} \mathrm{N}, 152.5^{\circ} \mathrm{E}-170^{\circ} \mathrm{E}$. The difference between these two areas is defined as the North Pacific dipole index in October. For November (Fig. 6b), the anticyclone center is located at $42.5^{\circ} \mathrm{N}-50^{\circ} \mathrm{N}, 172.5^{\circ} \mathrm{W}-155^{\circ} \mathrm{W}$, and the center of the anomalous cyclone is located at $24^{\circ} \mathrm{N}-31.5^{\circ} \mathrm{N}$, $165^{\circ} \mathrm{E}-177.5^{\circ} \mathrm{W}$. These results show that the correlation coefficients between the AO and DCA in October and November are 0.48 and 0.57 , respectively, which are statistically significant at the $95 \%$ confidence level using a twotailed Student's t-test (Table 2). These results indicate that the North Pacific dipole pattern plays an important role in the spreading process of the AO. However, the correlation coefficients between the precipitation in the SCSA and the DCA in October and November are only 0.17 and -0.24 , respectively, which are not statistically significant.

The southern wave train is described by the $200 \mathrm{hPa}$ meridional winds, and three meridional winds regions are selected according to Fig. 6. In October (Fig. 6a), the normalized area-weighted averages of the meridional winds are denoted as v1 $10, \mathrm{v} 2 \_10$ and v3 10 for region one $\left(40^{\circ} \mathrm{E}-50^{\circ} \mathrm{E}, 22.5^{\circ} \mathrm{N}-30^{\circ} \mathrm{N}\right)$, region two
Table 2 Correlation coefficients between the different index in October and November during 1979-2014

\begin{tabular}{lllcc}
\hline & DCA Oct & SWT Oct & DCA Nov & SWT Nov \\
\hline AO Oct & $0.48^{* *}$ & $0.61^{* *}$ & & \\
Pre Oct & 0.17 & $0.48^{* *}$ & & \\
AO Nov & & & $0.57^{* *}$ & $0.39^{*}$ \\
Pre Nov & & & -0.24 & $-0.53^{* *}$ \\
\hline
\end{tabular}

*Statistically significant at the $95 \%$ confidence level

** Statistically significant at the $99 \%$ confidence level

$\left(70^{\circ} \mathrm{E}-80^{\circ} \mathrm{E}, 22.5^{\circ} \mathrm{N}-30^{\circ} \mathrm{N}\right)$ and region three $\left(115^{\circ} \mathrm{E}-125^{\circ} \mathrm{E}\right.$, $22.5^{\circ} \mathrm{N}-30^{\circ} \mathrm{N}$ ), respectively. The southern wave train index in October (SWT_Oct) is collectively expressed as v1_10-v2_10-v3_10. Similarly, in November (Fig. 6b), the normalized area-weighted averages of the meridional winds in region one $\left(55^{\circ} \mathrm{E}-65^{\circ} \mathrm{E}, 15^{\circ} \mathrm{N}-22.5^{\circ} \mathrm{N}\right)$, region two $\left(75^{\circ} \mathrm{E}-85^{\circ} \mathrm{E}, 15^{\circ} \mathrm{N}-22.5^{\circ} \mathrm{N}\right)$ and region three $\left(115^{\circ} \mathrm{E}-125^{\circ} \mathrm{E}\right.$, $\left.15^{\circ} \mathrm{N}-22.5^{\circ} \mathrm{N}\right)$ are denoted as v1_11, v2_11 and v3_11, respectively, and the southern wave train index in November (SWT_Nov) is expressed as v1_11-v2 $11+\mathrm{v} 3 \_11$. In October and November, the correlation coefficients between the SWT and the AO reach as high as 0.61 and 0.39 , respectively, which are statistically significant at the 
99\% confidence level (Table 2), while the correlation coefficients between the SWT and precipitation in October and November are 0.48 and -0.53 , respectively, which are statistically significant at the $99 \%$ confidence level.

These results indicate that the influences of the Oct/Nov AO on the precipitation over the SCSA are closely related to the SWT. Hence, composite and regression analysis are carried out to further study the impacts of the SWT on atmospheric circulation anomalies. Figure 7 presents the regression coefficient distributions of the SWT-related circulation anomalies in October and November during 1979-2014. Comparing Figs. 5a-c and $7 \mathrm{a}-\mathrm{c}$, the SWT-related circulation anomalies are similar to the AO-related circulation in October, especially for the the $200 \mathrm{hPa}$ zonal winds fields. There

(a) Oct

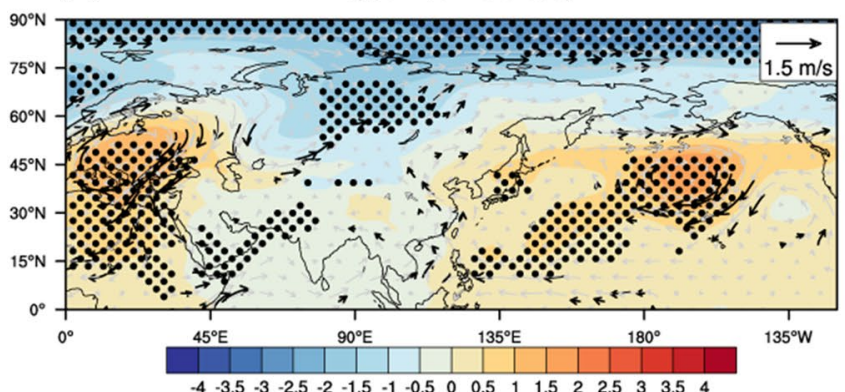

(b) Oct

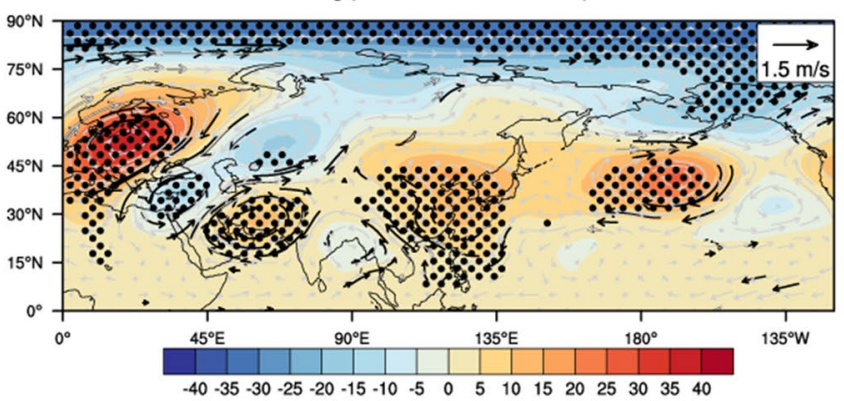

(c) Oct

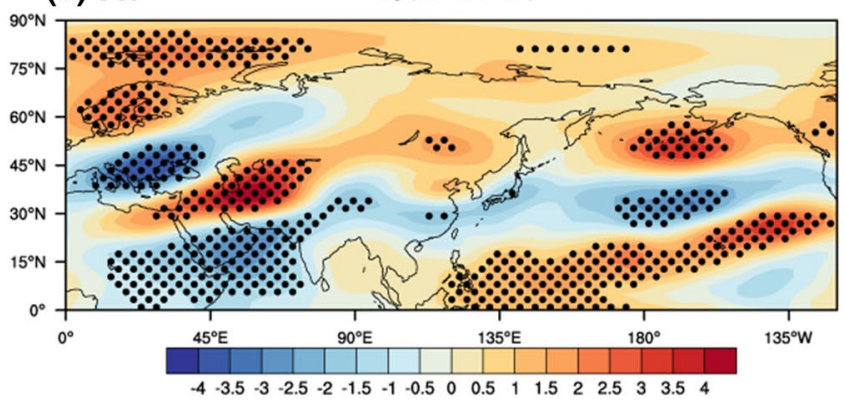

Fig. 7 Regression coefficients between the following variables and the AO index in October during 1979-2014: a wind at $850 \mathrm{hPa}$ (vectors, units: $\mathrm{m} / \mathrm{s}$ ) and SLP (shading, units: hPa), b geopotential height (shading, units: hgm) and wind (vectors, units: $\mathrm{m} / \mathrm{s}$ ) at $500 \mathrm{hPa}$ and c zonal wind at $200 \mathrm{hPa}$ (units: $\mathrm{m} / \mathrm{s}$ ). $\mathbf{d}-\mathbf{f}$ are the same as a-c, but in are significant differences in the atmospheric circulation fields between October and November (Fig. 7d-f). In the $200 \mathrm{hPa}$ zonal winds fields, no significant band-like anomaly distribution is observed, while discontinuously distributed anomaly centers appear in November.

The composite analysis of the SWT-related precipitation anomalies in October and November are shown in Fig. 8. And the standard deviation is 0.5 . Under the higher October SWT, significant positive precipitation appears in Thailand, Myanmar and Vietnam (Fig. 8a), which is similar to the distribution in Fig. 2a. In contrast, under the lower October SWT, the precipitation is negative in most of the study area. The distribution of the difference (Fig. 8c) demonstrates that the precipitation is increasing in most of the northwestern

(d) Nov $\operatorname{Reg}($ SWT, SLP \& UV850)

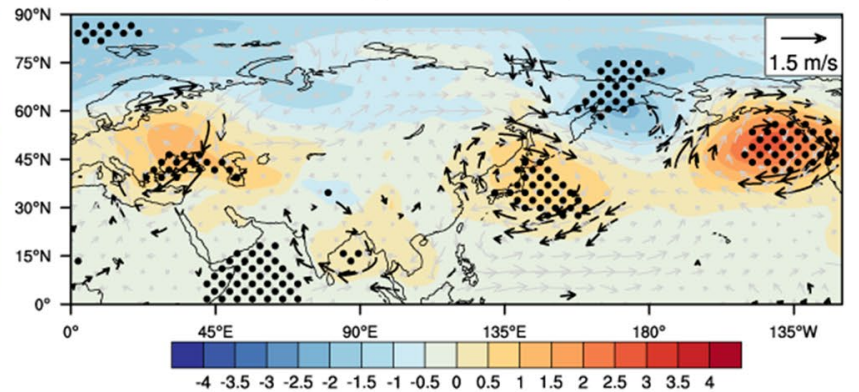

(e) Nov

Reg ( SWT, GPH500 \& UV500)

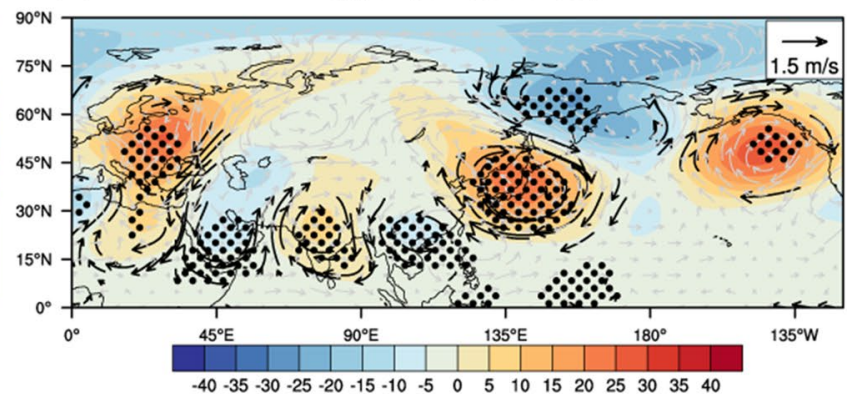

(f) Nov

$\operatorname{Reg}(\mathrm{SWT}, \mathrm{U} 200$ )

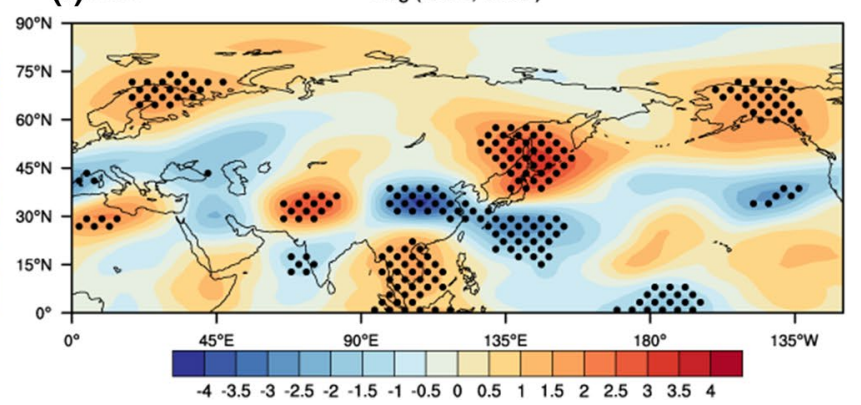

November. Dotted regions indicate statistical significance at the $95 \%$ confidence level using a two-tailed Student's t-test. Black and gray arrows indicate that both components of the wind anomalies are statistically significant and nonsignificant, respectively, at the $90 \%$ confidence level 
(a) Oct

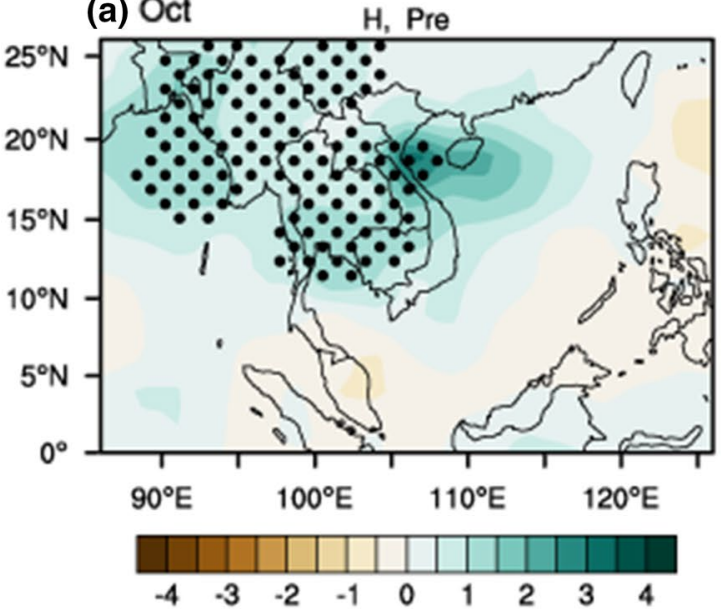

(b) Oct

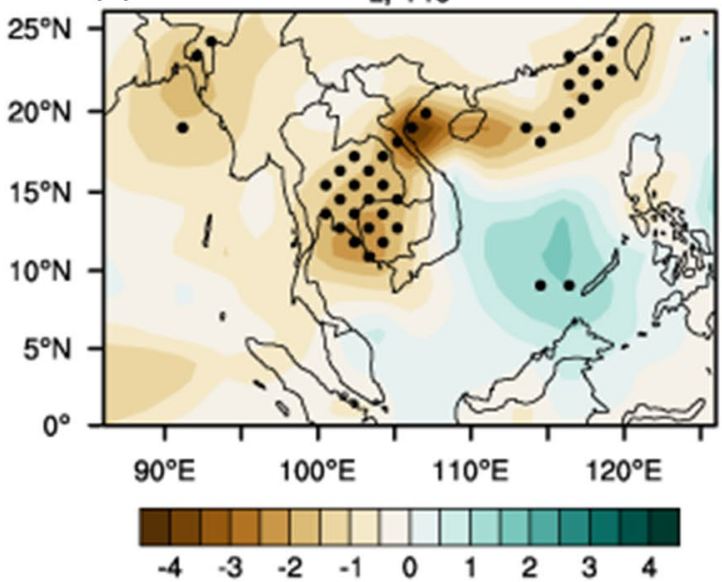

(c) Oct

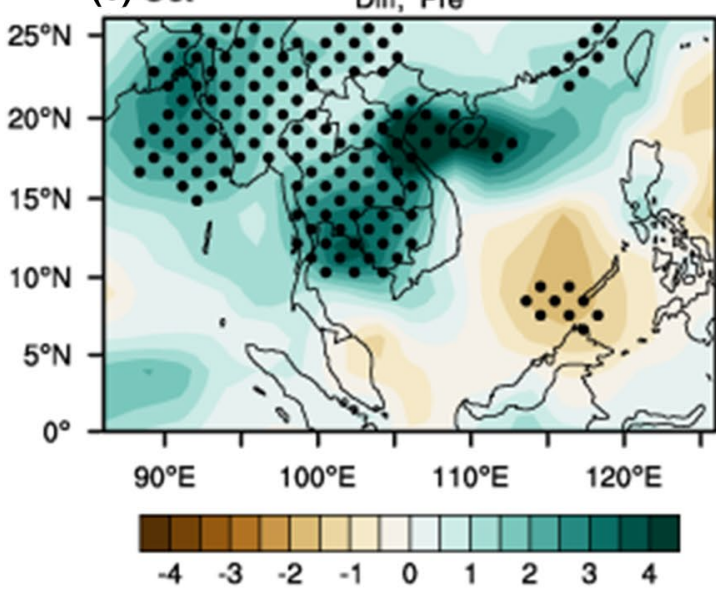

Fig. 8 Composite anomalies of the precipitation (units: $\mathrm{mm} / \mathrm{d}$ ) corresponding to the a higher (H), b lower (L) SWT index, $\mathbf{c}$ their difference (H-L) in October during 1979-2014. d-f are the same as a-c, (d) Nov H, Pre

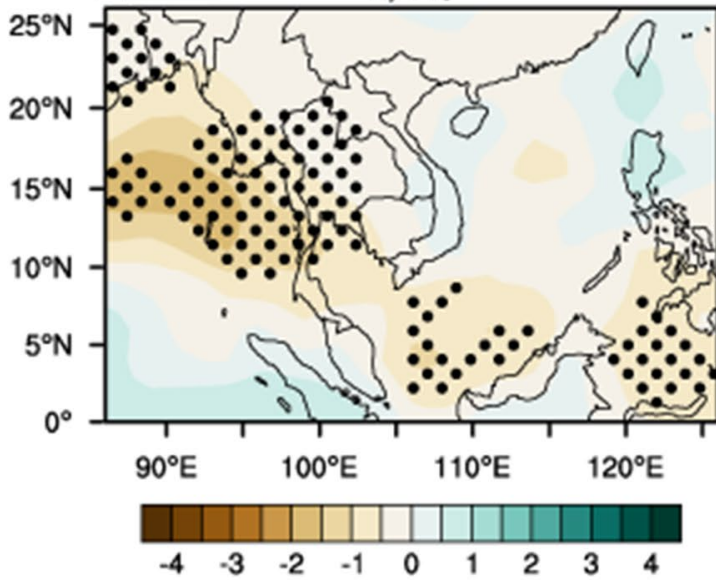

(e) Nov

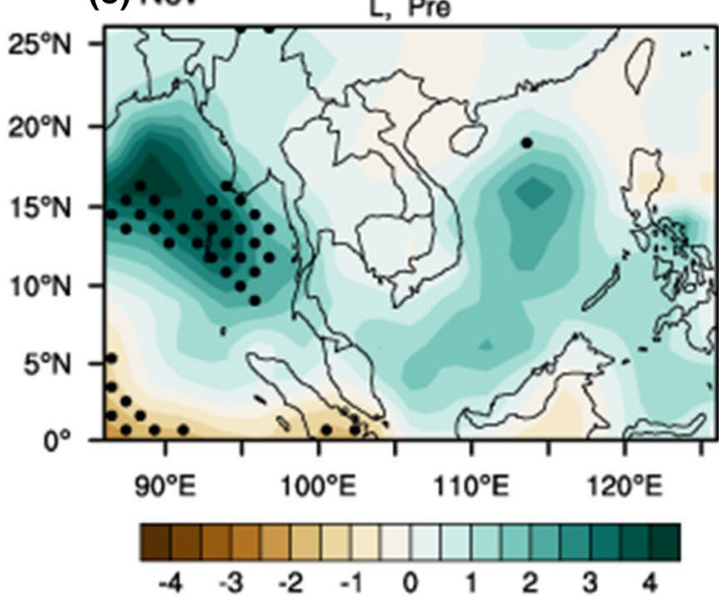

(f) Nov

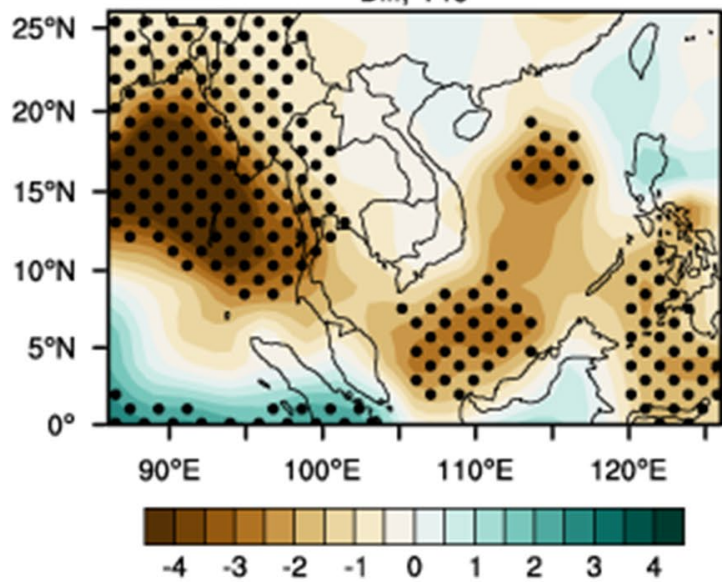

but in November. Dotted regions indicate statistical significance at the 95\% confidence level using a two-tailed Student's t-test 
extent of the study area. In November (Fig. 8d-f), the precipitation is decreasing over the Bay of Bengal and the South China Sea due to the higher SWT, and the precipitation's decreasing is more obvious in the the differences fileds (Fig. 8f), which is similar to the distribution shown in Fig. 2b.

Figure 9 shows the distributions of the regression coefficients between the AO index and the $200 \mathrm{hPa}$ quasigeostrophic streamfunction, wave activity flux (WAF), RWS and divergent winds. In October (Fig. 9a), corresponding to the positive phase of the $\mathrm{AO}$, an anomalous wave train originates from the North Atlantic with two paths: an eastward propagation path is passing through the Mediterranean and traveling further to East Asia and the North Pacific, and a southeastward propagation path is traveling to the Arabian Sea and further to East Asia. However, the Rossby wave guided by westerlies tends to trigger positive streamfunction anomalies in the upper troposphere over the Middle East and South Asia region in October, while there are negative streamfunction anomalies in November (Fig. 9c). The most notable feature in Fig. 9 is the obvious upper-level convergence and RWS anomalies over the Euro-Atlantic midlatitude and the northern North Pacific both in October and November. The positive RWS anomalies are located mainly at approximately $25^{\circ}-35^{\circ} \mathrm{N}, 50^{\circ}-70^{\circ} \mathrm{E}$ in October, which may facilitate the propagation of Rossby waves, while negative RWS anomalies are located in this region in November. Specifically, there are obvious upper-level convergence and positive RWS anomalies over the northern North Pacific in October. In contrast, divergence anomalies appear in the tropical North Pacific and convergence anomalies appear in the subtropical North Pacific in November. The AO-related patterns of upper-level RWS anomalies and convergence over the North Pacific and their apparent intraseasonal contrasts may be associated with the cyclonic and anticyclonic circulation anomalies at lower level. Furthermore, these contrasts may have implications for the relationships between the AO and precipitation anomalies over the SCSA in October and November.

\subsection{AO-associated SST evolution in the North Pacific}

The atmospheric circulation anomalies associated with the AO may also be affected by sea-atmosphere interactions ( $\mathrm{He}$ and Wang 2013). Some studies indicated that the warmer SST in the eastern Pacific is associated with an anomalous lower-tropospheric anticyclone located in the South China Sea and Philippine Sea, causing anomalously wet conditions over southern China (Wang et al. 2000, 2001; Wu et al. 2003; Feng and Li 2011; Chen et al. 2014). SST may bridge AO and climate over SCSA, and have significant influence on atmospheric circulation anomalies in the Pacific region, so we exam the SST anomalies in the Pacific. We further illustrate the anomalies associated with the Oct/Nov AO in Figs. 10 and 11, including the evolution of SST, sea surface temperature tendency (dsst), turbulent heat flux, $10 \mathrm{~m}$ winds
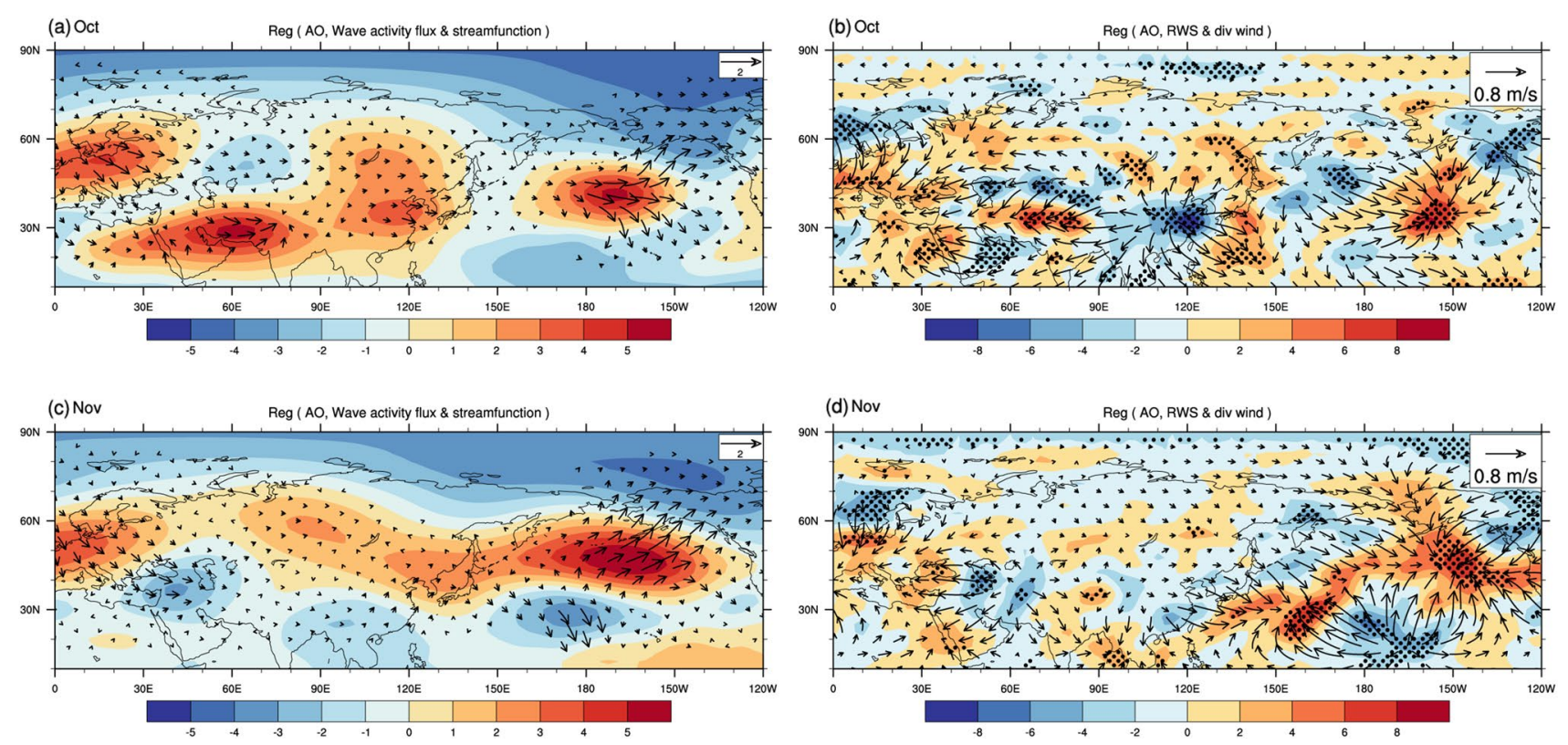

Fig. 9 Regression coefficients between the $200 \mathrm{hPa}$ variable fields and the AO index in October during 1979-2014: a quasigeostrophic streamfunction (shading, units: $10^{6} \mathrm{~m}^{2} \mathrm{~s}^{-1}$ ) and wave activity flux (vectors, units: $\mathrm{m}^{2} \mathrm{~s}^{-2}$ ) and b RWS (shading, units: $10^{-11} \mathrm{~s}^{-2}$ ) and

divergent wind (vectors, units: $\mathrm{m} / \mathrm{s}$ ). $\mathbf{c}, \mathbf{d}$ are the same as $\mathbf{a}, \mathbf{b}$, but in November. Dotted regions indicate statistical significance at the $95 \%$ confidence level using a two-tailed Student's t-test 
(a) Oct

$\operatorname{Reg}(\mathrm{AO}, \mathrm{SST})$

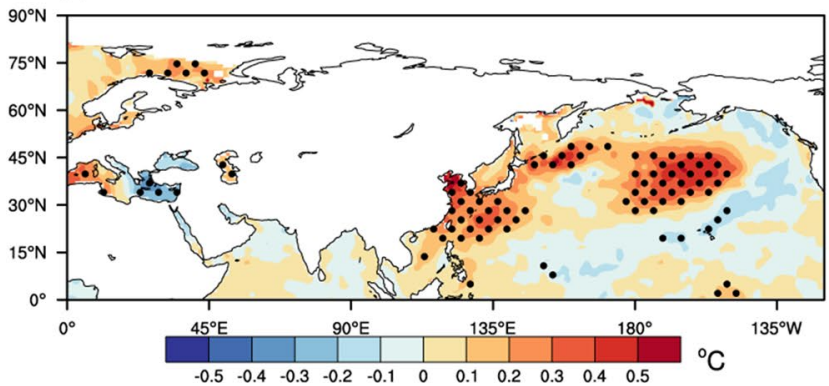

(c) Oct

$\operatorname{Reg}(A O, T H F \& 10 m$ UV $)$

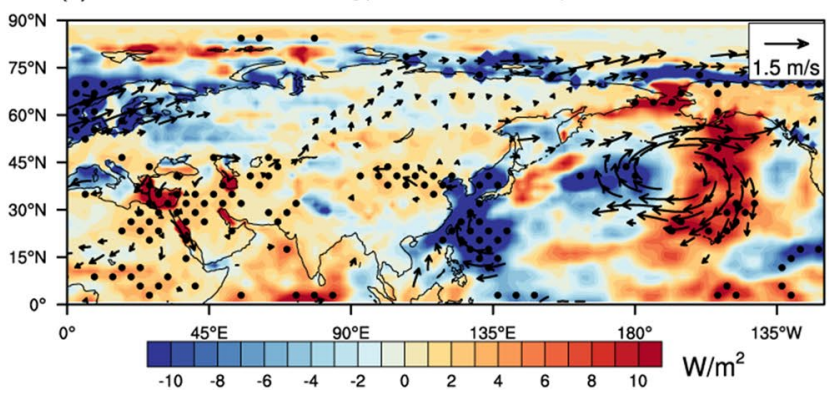

Fig. 10 Regression coefficients between the following variables and the AO index in October during 1979-2014: a sea surface temperature (SST, units: ${ }^{\circ} \mathrm{C}$ ), b sea surface temperature tendency (dsst, units: ${ }^{\circ} \mathrm{C}$ ), $\mathbf{c}$ turbulent heat flux (shading, units: $\mathrm{W} / \mathrm{m}^{2}$ ) and horizontal surface wind at $10 \mathrm{~m}$ (vector, units: $\mathrm{m} / \mathrm{s}$ ) and $\mathbf{d}$ total cloud cover (TCDC, units: \%). Dotted regions indicate statistical significance at the $90 \%$ (b) Oct $\quad \operatorname{Reg}(\mathrm{AO}, \mathrm{dsst})$

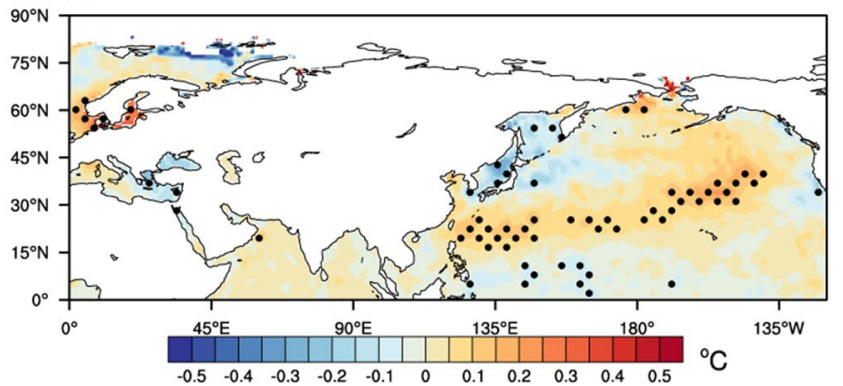

(d) Oct

$\operatorname{Reg}(A O, T C D C)$

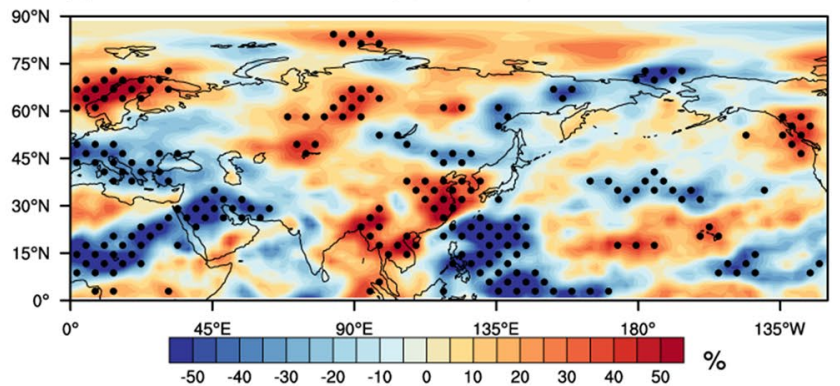

confidence level using a two-tailed Student's t-test. Black arrows indicate that both components of the wind anomalies are statistically significant at the $90 \%$ confidence level. Positive heat flux anomalies indicate the transfer of heat flux from the ocean to the atmosphere, and vice versa (a) Nov

$\operatorname{Reg}(\mathrm{AO}, \mathrm{SST})$

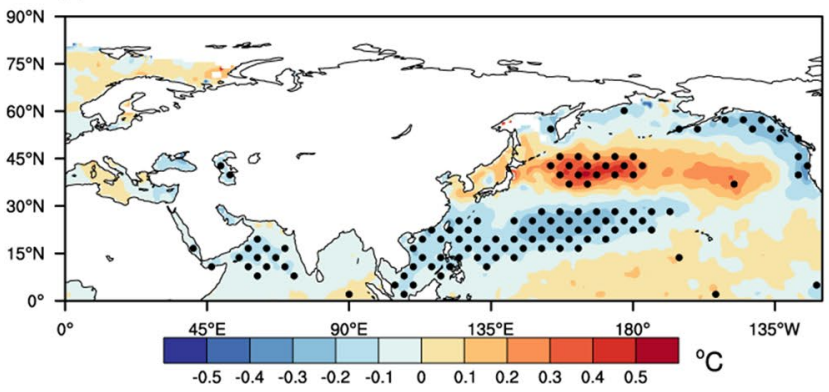

(c) Nov

$\operatorname{Reg}(A O, T H F \& 10 \mathrm{~m}$ UV $)$

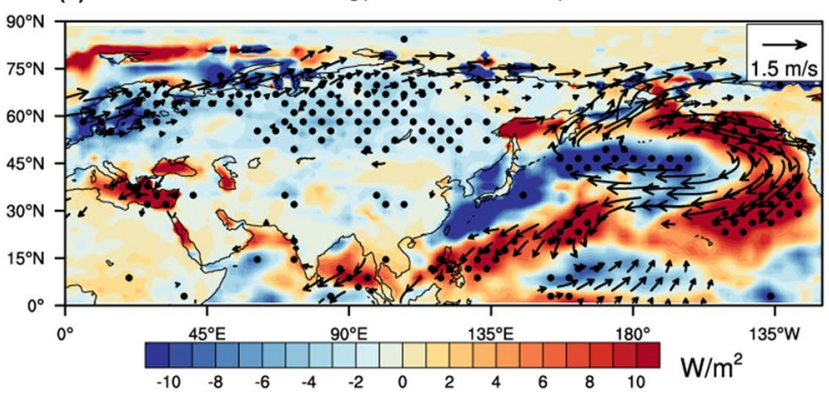

(b) Nov

$\operatorname{Reg}(\mathrm{AO}, \mathrm{dsst})$

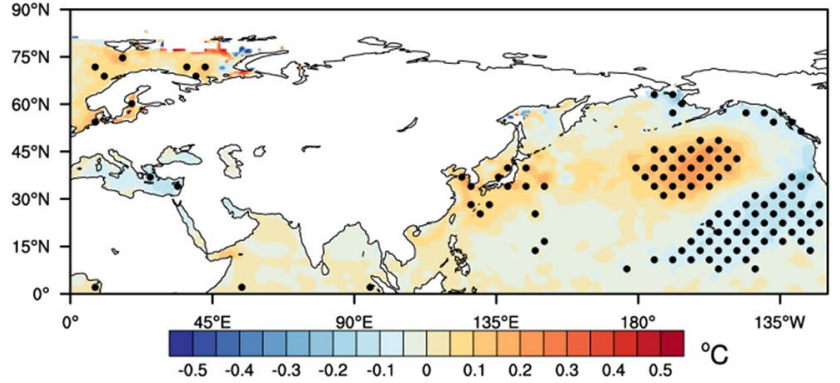

(d) Nov

$\operatorname{Reg}(\mathrm{AO}, \mathrm{TCDC})$

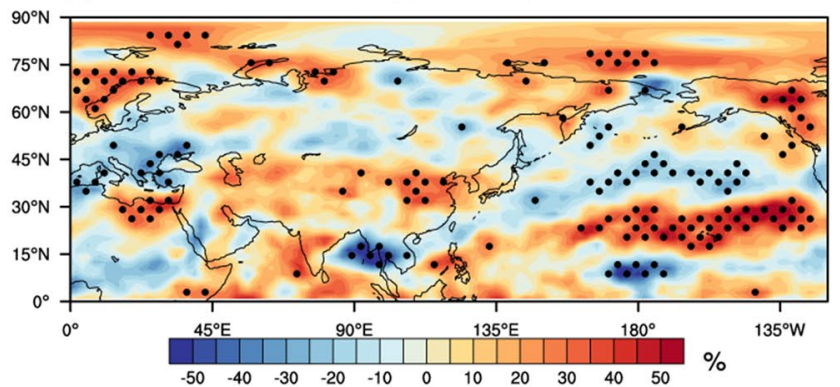

Fig. 11 The same as Fig. 10, but in November 
and total cloud cover (TCDC). The SST tendency in a specific month is defined as the SST in the succeeding month minus the SST in the preceding month divided by 2 , and the SST tendency is calculated by the central difference method.

A horseshoe-shaped SST anomaly preliminarily takes shape both in October and November, which is first observed by Liu et al. (2006). Comparing Figs. 10a and 11a, it can be seen that the range of colder-than-normal SSTs in the North Pacific is greater in November than in October. The structure of the SST tendency field is similar to that of the SST field. Furthermore, the total cloud cover anomalies in the SCSA are significantly more in October than in November (Figs. 10d, 11d), which provides a possible dynamic condition for the precipitation's incerasing in this area.

Figure 10c shows an apparent anticyclone over the North Pacific related to the simultaneous occurrence of the Oct AO that contributes to the formation of the horseshoe-shaped SST anomalies. To the south of the anticyclone $\left(10^{\circ} \mathrm{N}-30^{\circ} \mathrm{N}, 140^{\circ} \mathrm{E}-125^{\circ} \mathrm{W}\right)$ and the north of it $\left(50^{\circ} \mathrm{N}-60^{\circ} \mathrm{N}, 175^{\circ} \mathrm{E}-130^{\circ} \mathrm{W}\right)$, the SST anomaly is negative (Fig. 10a), whereas the SST is abnormally positive in the center of the anticyclone. The significant anticyclone in $30^{\circ} \mathrm{N}-50^{\circ} \mathrm{N}, 170^{\circ} \mathrm{E}-140^{\circ} \mathrm{W}$ in October can be developed a dipole-like pattern in the form of cyclones $\left(0^{\circ} \mathrm{N}-30^{\circ} \mathrm{N}, 145^{\circ} \mathrm{E}-150^{\circ} \mathrm{W}\right)$ and anticyclones $\left(35^{\circ} \mathrm{N}-60^{\circ} \mathrm{N}, 150^{\circ} \mathrm{E}-135^{\circ} \mathrm{W}\right.$ ) in November (Figs. 10c, 11c). The climatological winds are present easterly winds and westerly winds over the significant anticyclone $\left(30^{\circ} \mathrm{N}-50^{\circ} \mathrm{N}, 170^{\circ} \mathrm{E}-140^{\circ} \mathrm{W}\right)$ east and west flanks, and the anticyclone acts to increase these winds on its east and west flanks (figure is not given). The turbulent heat flux dominates the net sea surface flux at the mid-latitudes. Positive heat flux anomalies indicate the transfer of heat flux from ocean to atmosphere. The combined effect of turbulent heat flux anomalies and the $10 \mathrm{~m}$ sea surface winds field anomalies (Fig. 10c) make the turbulent heat increasing and local SST decreasing (Fig. 10a), which in turn could effectively form an anomalous anticyclone over the North Pacific by strengthening the northern temperature gradient and weakening the southern temperature gradient. Finally, the dipole pattern in the form of cyclones and anticyclones over the North Pacific is strengthened in November. SST has significant effect to the dipole pattern circulation, however, the directly effect between SST and precipitation over SCSA is not significant in October and November (figure is not given), maybe SST have effect by the dipole pattern circulation on precipitation over SCSA indirectly. This part deserves further study in the future.

\subsection{Validation by CMIP6 model simulations}

To test whether the coupled models can represent the reversed responses of the $\mathrm{AO}$ on the precipitation in October and
November, we use the simulations (historical experiments) of eleven models from the Coupled Model Intercomparison Project phase 6 (CMIP6) during the period 1979-2014 (see Table 1). We exam the basic structure of AO mode in CMIP6 models (figure is not given), results show that the models can capture the basic structure of $\mathrm{AO}$ in general, although some models show bias in both strength and the location of AO. We select three CMIP6 models (CAMS-CSM1-0, CanESM5, and CESM2-WACCM) that can be driven primarily by their capability to reproduce the spatial and temporal patterns of the observed fields since 1979. These models are called "CMIP6 HIGH-r", which have higher correlation coefficients between $\mathrm{AO}$ and precipitation. In contrast, we select the other 8 models that poorly simulate the impact of $\mathrm{AO}$ on the atmospheric circulation and refer to these models as "CMIP6 LOW-r", which have lower correlation coefficients between $\mathrm{AO}$ and precipitation. Here, we provide the ensemble mean results of the model simulations.

Using this CMIP6 subset, which we refer to as CMIP6 HIGH-r, we calculate the correlation coefficient between the $\mathrm{AO}$ and precipitation in October is 0.42 (significant at the 99\% confidence level) during 1979-2014. In addition, the CMIP6 HIGH-r simulation can reproduce the negative correlation over Thailand and its neighboring areas in November. However, this simulation overestimates the response of the $\mathrm{AO}$ on precipitation in the Bay of Bengal (Fig. 12b). In contrast to CMIP6 HIGH-r, the CMIP6 LOW-r simulation results are poor both in October and November. As shown in Fig. 12, the CMIP6 HIGH-r simulation better reproduces the reversed relationships between $\mathrm{AO}$ and precipitation over the SCSA in October and November than does CMIP6 LOW-r. Figures 13 and 14 illustrate the regression maps of the October and November ensemble-mean atmosphere circulation fields with AO in the CMIP6 HIGH-r and CMIP6 LOW-r simulations. Both sets of models can capture the change from an anticyclone over the North Pacific in October to the dipole-like pattern in November. However, the $200 \mathrm{hPa}$ zonal wind anomaly in the Arabian Sea region and its neighboring continents in October can be reproduced only by CMIP6 HIGH-r. Moreover, CMIP6 LOW-r cannot simulate the observed dominant "positive-negative-positive-negative" distribution in the upper-level troposphere moving from West Europe to the Arabian Sea in November. To some extent, the physical linkages between $\mathrm{AO}$ and the reversed precipitation in October and November can be reproduced by CMIP6 HIGH-r.

\section{Summary and discussion}

In this paper, we investigate the reversed relationships between Oct/Nov AO and precipitation over the SCSA during 1979-2014. The influences of Oct/Nov AO on 
(a) Oct

CMIP6 HIGH-r

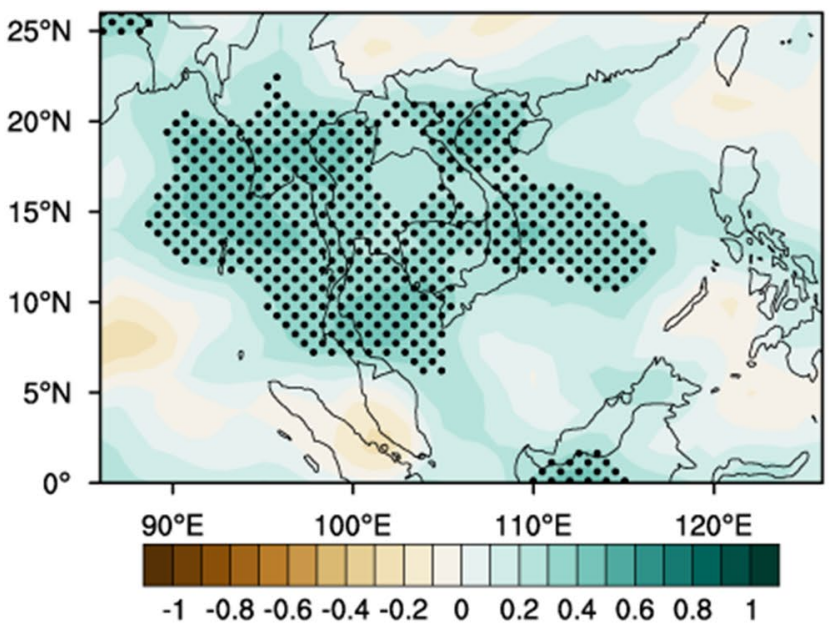

(c) Oct

CMIP6 LOW-r

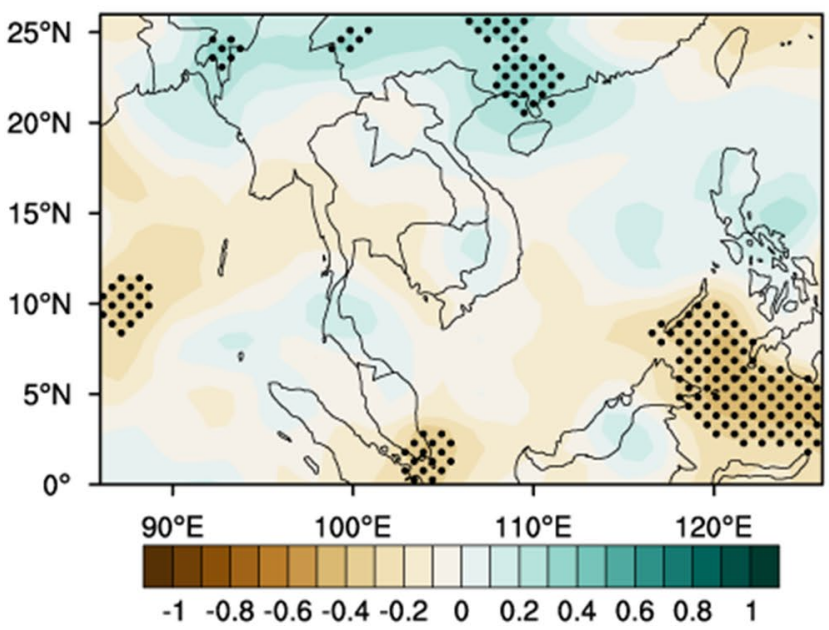

Fig. 12 Spatial distributions of the correlation coefficients between the AO index and precipitation in October (a) and November (b) on the basis of CMIP6 HIGH-r; dotted regions indicate significance at

precipitation in the study region and the possible mechanisms are discussed. The main conclusions are as follows.

In most areas of the SCSA, the correlation coefficients between $\mathrm{AO}$ and precipitation in October and November are 0.44 and -0.31 , which are statistically significant at the $99 \%$ and $90 \%$ confidence levels, respectively. There are 21 years when the October $\mathrm{AO}$ and precipitation are in phase, accounting for approximately $58.3 \%$ of all events, and there are 24 years when the November AO and precipitation are out of phase, accounting for approximately $66.7 \%$ of all events. In October, the specific humidity shows significant positive anomalies in most of the SCSA, and the water vapor transported by the southerly winds provides favorable conditions for the precipitation in this region. In contrast, the specific humidity accompanied by (b) Nov

CMIP6 HIGH-r

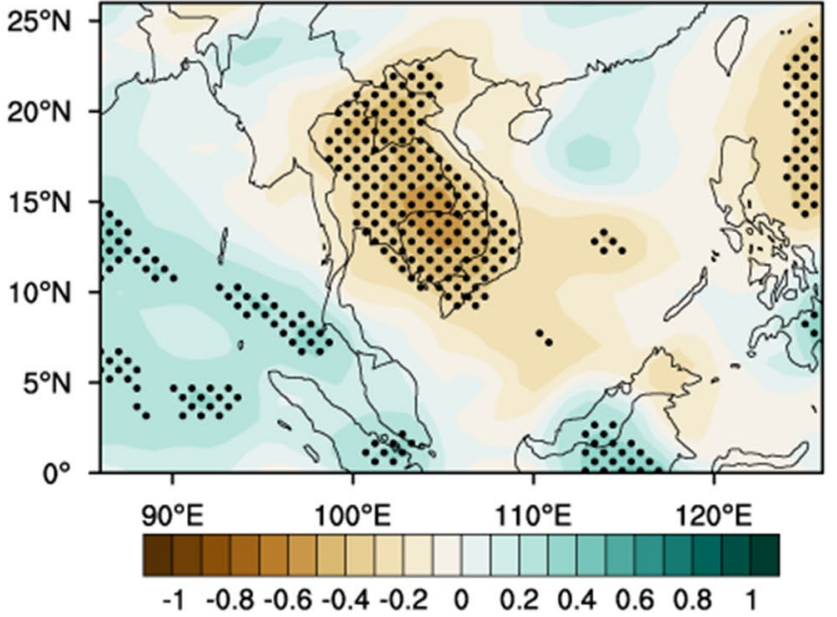

(d) Nov CMIP6 LOW-r

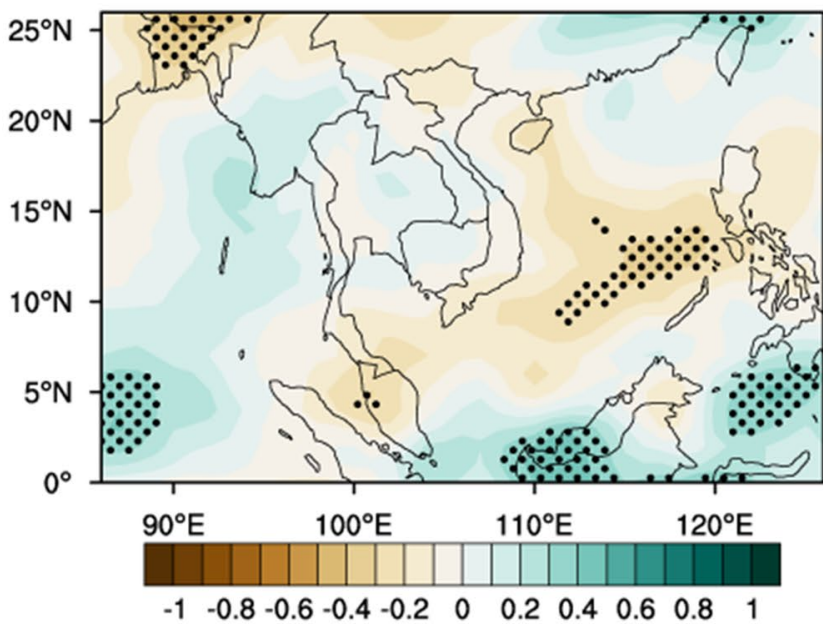

the 95\% confidence level using a two-tailed Student's t-test. c and d are the same as a and $\mathbf{b}$, but on the basis of CMIP6 LOW-r

the northerly winds in November presents negative anomalies, and less water vapor is transported to the SCSA, which may lead to less precipitation in this region. The significant upward air movement from ground to the upper troposphere $(1000-150 \mathrm{hPa})$ is observed between $10^{\circ} \mathrm{N}$ and $30^{\circ} \mathrm{N}$ with more total cloud cover in October, creating possible dynamic conditions for the precipitation's increasing over the SCSA. In November, there is downward air motion between $10^{\circ} \mathrm{N}$ and $20^{\circ} \mathrm{N}$ with less total cloud cover, which may result in precipitation's decreasing over the SCSA. Moisture budget diagnosis suggests that the increase of precipitation in October mainly contributed by zonal moisture flux convergence $\left(-\partial_{\mathrm{x}}(\overline{\mathrm{uq}})\right)$ and its decrease in November mainly contributed by zonal divergence. 


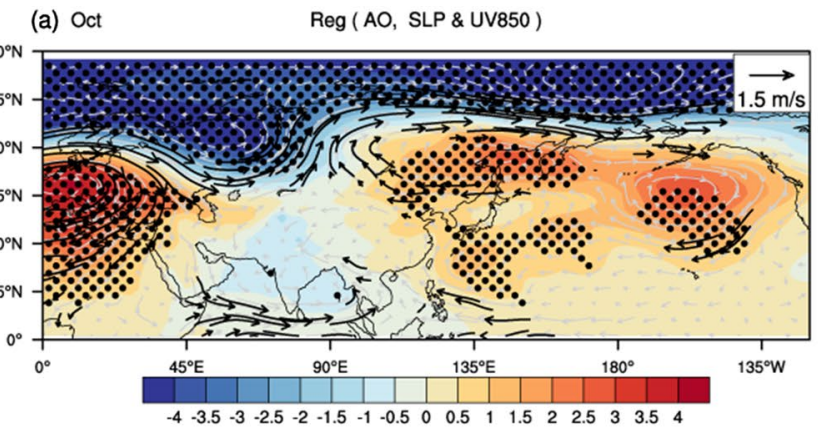

(b) Oct

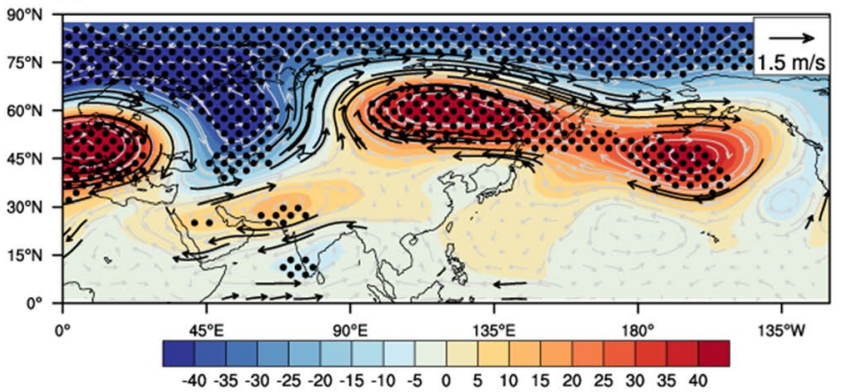

(c) Oct

Reg ( AO, U200)

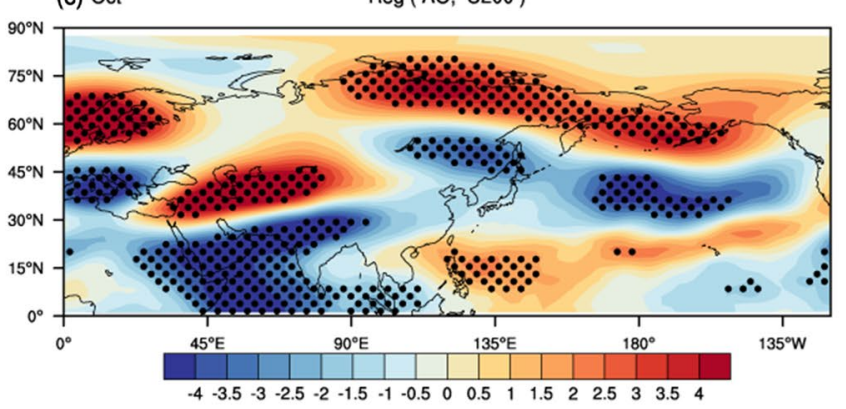

Fig. 13 The same as Fig. 5, but on the basis of CMIP6 HIGH-r

Regressive analysis reveal that the significant positive geopotential height anomalies and anticyclonic circulation anomalies over the Arabian Sea appears in the $200 \mathrm{hPa}$ winds fields in October, while there are anomalous anticyclones and cyclones moving from North Africa through the Arabian Sea and the Bay of Bengal to the South China Sea in November. The anomalous RWS and divergent winds in the upper troposphere stimulate the appearance of an anomalous anticyclone in October over the North Pacific, while the anomalies develop into a dipole pattern in the form of cyclones and anticyclones in November. Further analysis reveal that the $\mathrm{AO}$ in October may increase precipitation through the southern wave train (SWT), which along with the westerly jet stream from North Africa to the Middle East and South China. The correlation coefficients between SWT and AO are as high as 0.61 and 0.39 in October and November, respectively, which are statistically significant at the $99 \%$ confidence level. For SWT and precipitation, the (d) Nov

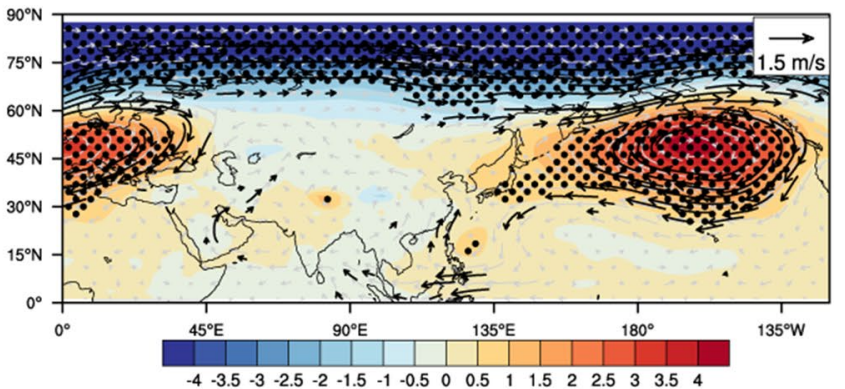

(e) Nov

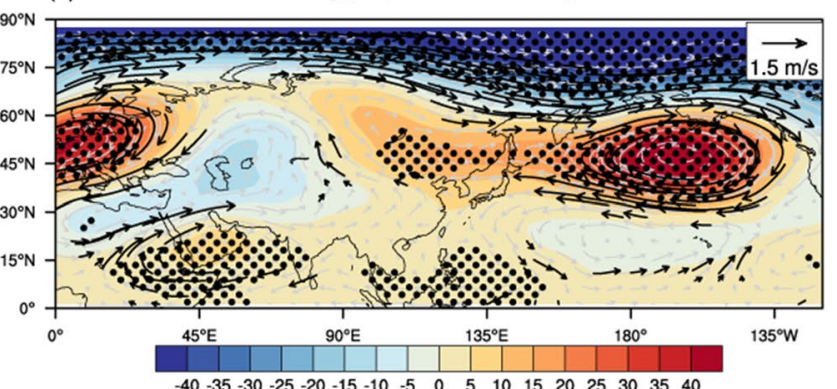

(f) Nov

$\operatorname{Reg}(\mathrm{AO}, \mathrm{U} 200)$

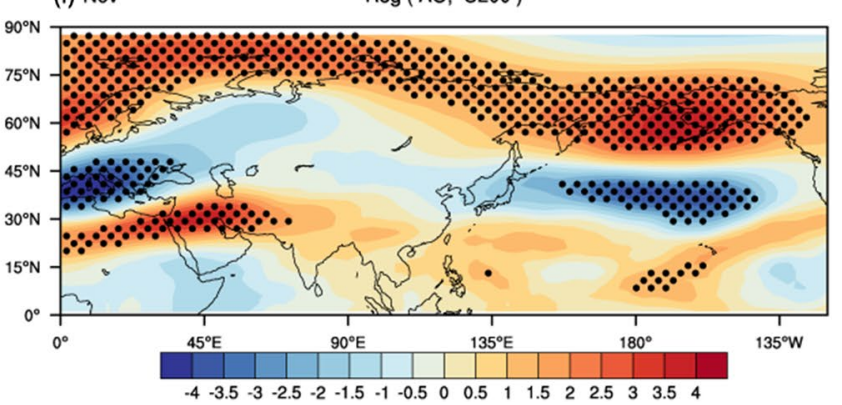

correlation coefficients are 0.48 and -0.53 in October and November, respectively, which are statistically significant at the $99 \%$ confidence level. These further indicate that the influences of the Oct/Nov $\mathrm{AO}$ on the precipitation over the SCSA are closely related to the SWT. Composite analysis show that under the influence of the positive Oct SWT, significant positive precipitation occurs in Thailand, Myanmar and the Bay of Bengal. Under the influence of the negative Oct SWT, precipitation is negative in most of the study area. In November, the precipitation is decreasing over the Bay of Bengal and South China Sea at the positive Nov SWT phase, while the precipitation is increasing at the negative Nov SWT phase.

In addition, air-sea interactions may exist over the North Pacific and affect the precipitation over the SCSA. Horseshoe-shaped SST anomalies are then formed with positive SST anomalies located in the central subtropical North Pacific and surrounded by negative SST anomalies. The 
(a) Oct

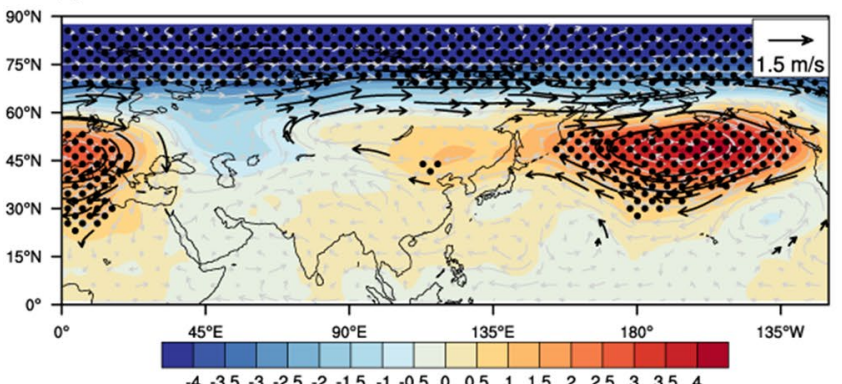

(b) Oct

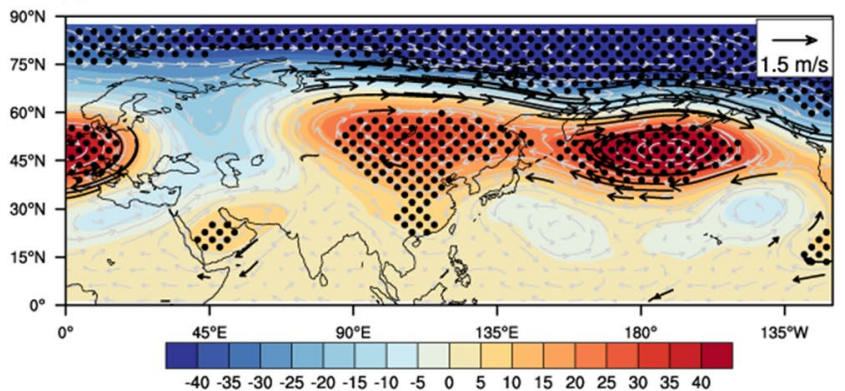

(c) Oct

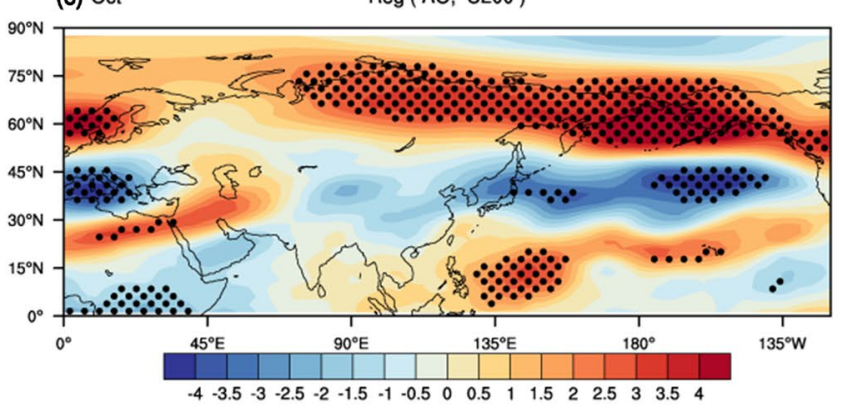

(d) Nov

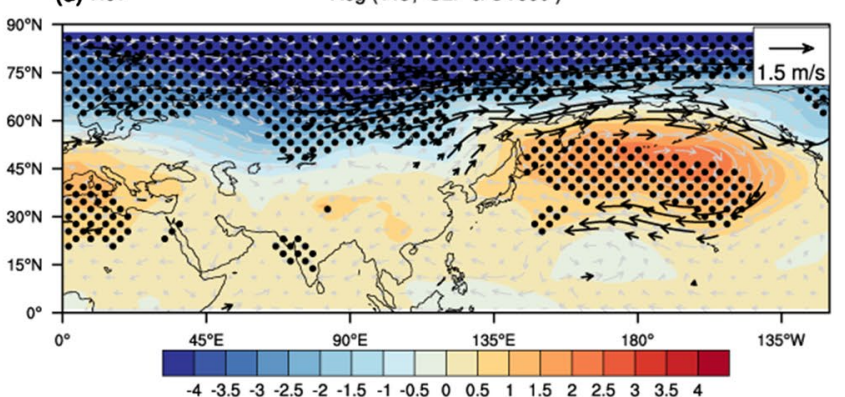

(e) Nov

$\operatorname{Reg}($ AO, GPH500 \& UV500)

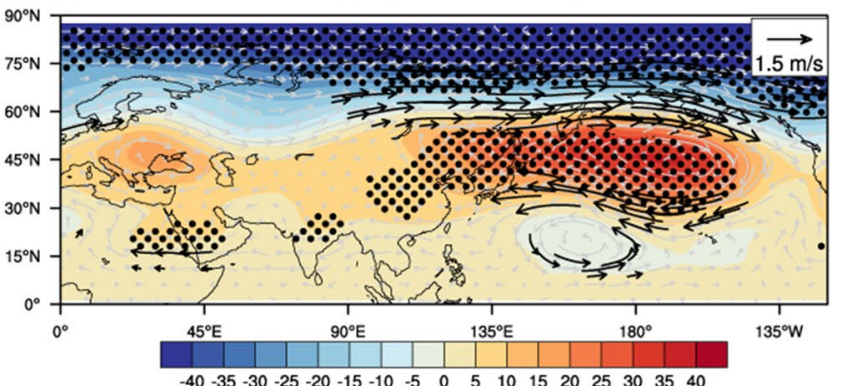

(f) Nov

$\operatorname{Reg}(\mathrm{AO}, \mathrm{U} 200)$

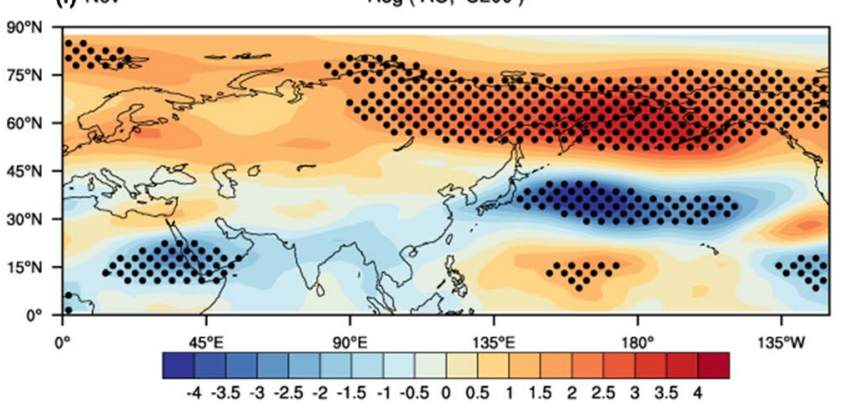

1979-2014. And CMIP6 HIGH-r can reproduce the negative correlation over Thailand and its neighboring areas in November. In contrast to CMIP6 HIGH-r, the CMIP6 LOW-r simulation results are poor in both October and November. To some extent, the physical linkages between $\mathrm{AO}$ and the reversed precipitation in October and November can be reproduced by the CMIP6 HIGH-r. The associated dynamical processes in this study are summarized in Fig. 15 schematically.

However, to better understand the dynamics of the feedback mechanism proposed in this paper, the numerical experiments are needed with coupled atmosphere-ocean model in the future. In regard of ocean-atmosphere feedback, this paper mainly focuses on SST changes in the Northwest Pacific. While Wei et al. (2017) indicated that the Indian Ocean warm pool and the central Pacific SST might impact precipitation over South China. Furthermore, other external factors, such as snow cover and sea ice, may 


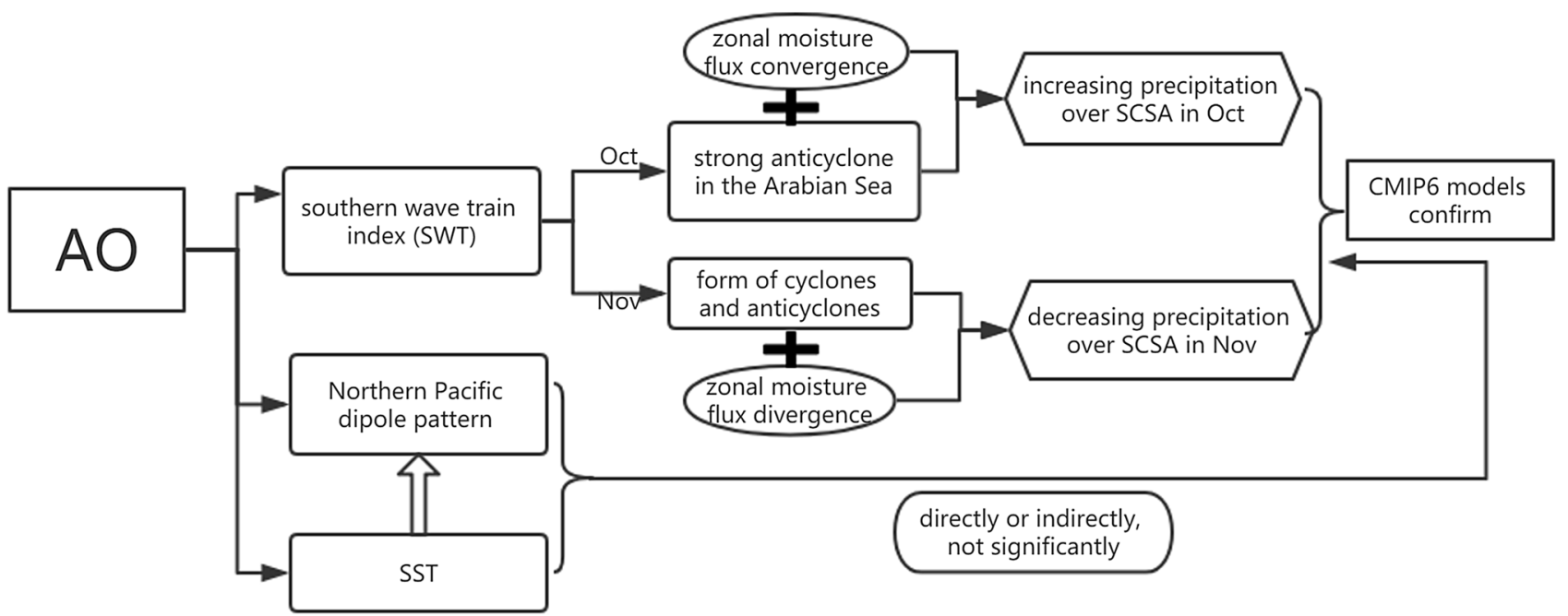

Fig. 15 Schematic diagram illustrating the mechanisms for the AO leading to the reversal of the precipitation over SCSA in October and November

contribute to the persistent impacts of the AO on precipitation. Therefore, further research is needed in this regard.

Acknowledgements This study is supported by National Key R\&D Program of China (2016YFA0602703), the National Natural Science Foundation of China (91644225). The NCEP-NCAR reanalysis data and GPCP precipitation data in this study are provided by the NOAA/ OAR/ESRL from their Web site at https://www.esrl.noaa.gov/psd. The CMIP6 data are obtained from this web site https://esgf-node.llnl.gov/ projects/cmip6/.

Author contributions Not applicable.

Funding The National Key Research and Development Program of China (2016YFA0602703), the National Science Foundation of China (91644225).

Availability of data and material The NCEP-NCAR reanalysis data and GPCP precipitation data in this study are provided by the NOAA/ OAR/ESRL from their web site at https://www.esrl.noaa.gov/psd. The CMIP6 data are obtained from this web site https://esgf-node.llnl.gov/ projects/cmip6/).

\section{Compliance with ethical standards}

Conflict of interest Not applicable.

Code availability Not applicable.

Open Access This article is licensed under a Creative Commons Attribution 4.0 International License, which permits use, sharing, adaptation, distribution and reproduction in any medium or format, as long as you give appropriate credit to the original author(s) and the source, provide a link to the Creative Commons licence, and indicate if changes were made. The images or other third party material in this article are included in the article's Creative Commons licence, unless indicated otherwise in a credit line to the material. If material is not included in the article's Creative Commons licence and your intended use is not permitted by statutory regulation or exceeds the permitted use, you will need to obtain permission directly from the copyright holder. To view a copy of this licence, visit http://creativecommons.org/licenses/by/4.0/.

\section{References}

Adler RF, Huffman GJ, Chang AF, Ferraro R, Xie PP, Janowiak JR, Bruno S, Udo C, Scott B, David G, Arnold S, Joel A, Philip N, Eric (2003) The version 2 global precipitation climatology project (GPCP) monthly precipitation analysis (1979-Present). J Hydrometeorol 4(6):1147-1167

Bader J, Mesquita MDS, Hodges KI, Keenlyside N, Osterhus S, Miles M (2011) A review on Northern Hemisphere sea-ice, storminess and the North Atlantic Oscillation: Observations and projected changes. Atmos Res 101:809-834. https://doi.org/10.1016/j.atmos res.2011.04.007

Boer GJ, Smith DM, Cassou C et al (2016) The decadal climate prediction project (DCPP) contribution to CMIP6. Geosci Model Dev 9:3751-3777

Branstator G (2002) Circumglobal teleconnections, the jet stream waveguide, and the North Atlantic Oscillation. J Clim 15:1893-1910

Chen JP, Wen ZP, Wu RG, Chen ZS, Zhao P (2014) Interdecadal changes in the relationship between southern China winter-spring precipitation and ENSO. Clim Dyn 43(5):1327-1338

Chen S, Chen W, Yu B (2017) The influence of boreal spring Arctic oscillation on the subsequent winter ENSO in CMIP5 models. Clim Dyn 29:1-3

Choi K, Kang S, Kim H (2013) Possible relationship between North Korean total rainfall and Arctic oscillation in May. Theor Appl Climatol 112:483-494. https://doi.org/10.1007/s0070 4-012-0738-3

Chou C, Lan CW (2012) Changes in the annual range of precipitation under global warming. J Clim 25:222-235

Choi K, Wu C, Byun H (2012) Possible connection between summer tropical cyclone frequency and spring Arctic oscillation over East Asia. Clim Dyn 38:2613-2629. https://doi.org/10.1007/s0038 2-011-1088-z 
Cullen HM, Kaplan A, Arkin PA, Demenocal PB (2002) Impact of the North Atlantic oscillation on middle eastern climate and streamflow. Clim Change 55:315-338

David WJT, Wallace JM (2000) Annular modes in the extratropical circulation. Part I: month-to-month variability. J Clim 13:10001016. https://doi.org/10.1175/1520-0442

Ebita A et al (2011) The Japanese 55-year reanalysis "JRA-55": an interim report. Sci Online Lett Atmos 7:149-152. https://doi. org/10.2151/sola.2011-038

Eyring V, Bony S, Meehl GA et al (2016) Overview of the coupled model intercomparison project phase 6 (CMIP6) experimental design and organization. Geosci Model Dev 9:1937-1958. https ://doi.org/10.5194/gmd-9-1937-2016

Feng G, Zou M, Qiao S, Zhi R, Gong Z (1980s) The changing relationship between the December North Atlantic oscillation and the following February East Asian trough before and after the late 1980s. Clim Dyn 51:4229-4242. https://doi.org/10.1007/s0038 2-018-4165-8

Feng J, Li JP (2011) Influence of El Niño Modoki on spring rainfall over South China. J Geophys Res 116(D13):102-111

Gao M, Yang J, Gong D (2014) Short communication unstable relationship between spring Arctic oscillation and East Asian summer monsoon. Int J Climatol 34:2522-2528

Gillett NP, Shiogama H, Funke B et al (2016) The detection and attribution model intercomparison project (DAMIP v1.0) contribution to CMIP6. Geosci Model Dev 9:3685-3697

Gong D, Wang S et al (2001) East Asian winter monsoon and Arctic oscillation. Geophys Res Lett 28:2073-2076

Gong D, Yang J, Kim SJ, Al E (2011) Spring Arctic oscillation-East Asian summer monsoon connection through circulation changes over the western North Pacific. Clim Dyn 37:2199-2216

Gong D, Wang S (2003) Influence of Arctic oscillation on winter climate over China. J Geogr Sci 13(2):208-216

Gong D, Gao Y, Guo D, Mao R, Yang J, Hu M, Gao M (2014) Interannual linkage between Arctic/North Atlantic oscillation and tropical Indian Ocean precipitation during boreal winter. Clim Dyn 42:1007-1027. https://doi.org/10.1007/s00382-013-1681-4

Griffies SM, Danabasoglu G, Durack PJ et al (2016) OMIP contribution to CMIP6: experimental and diagnostic protocol for the physical component of the Ocean Model Intercomparison Project. Geosci Model Dev 9:3231-3296

Haarsma RJ, Roberts MJ, Vidale PL et al (2016) High Resolution Model Intercomparison Project (HighResMIP v1.0) for CMIP6. Geosci Model Dev 9:4185-4208

He S, Wang H (2013) Impact of the November December Arctic oscillation on the following January temperature in East Asia. J Geophys Res Atmos 118:981-998

He S, Gao Y, Li F, Wang H, He Y (2017) Impact of Arctic oscillation on the East Asian climate: a review. Earth Sci Rev 164:48-62

Hu M, Gong D, Wang L, Zhou T, Zhang Z (2012) Possible influence of January-March Arctic oscillation on the convection of tropical North Pacific and North Atlantic. Acta Meteorologica Sinica 70:479-491 (in Chinese)

Hurrell JW (1995) Decadal trends in the North Atlantic oscillation: regional temperatures and precipitation author(s). Science 269:676-679

Rm J, Rd P, Fc K (1999) Oceanic forcing of the wintertime North Atlantic oscillation and European climate. Nature 398:320-323

Jeong J, Ho C (2005) Changes in occurrence of cold surges over east Asia in association with Arctic oscillation. Geophys Res Lett. https://doi.org/10.1029/2005GL023024

Kageyama M, Braconnot P, Harrison SP et al (2018) The PMIP4 contribution to CMIP6. Part 1: overview and over-arching analysis plan. Geosci Model Dev 11:1033-1057

Kalnay E, Kanamitsu M, Kistler R, Collins W, Deaven D, Gandin L, Joseph D (1996) The NCEP/NCAR 40-Year Reanalysis Project.
Bull Am Meteorol Soc 77:437-471. https://doi.org/10.1175/15200477(1996)077<0437:TNYRP $>2.0$

Kim H, Ahn J (2012) Possible impact of the autumnal North Pacific SST and November AO on the East Asian winter temperature. J Geophys Res Atmos. https://doi.org/10.1029/2012JD017527

Kobayashi S, Ota Y, Harada Y, Ebita A, Moriya M, Onoda H, Onogi K, Kamahori H, Kobayashi C, Endo H, Miyaoka K, Takahashi K (2015) The JRA-55 reanalysis: general specifications and basic characteristics. J Meteorol Soc Jpn 93:5-48

Li F, Wang H, Gao Y (2014) On the strengthened relationship between the East Asian Winter Monsoon and Arctic oscillation: a comparison of 1950-70 and 1983-2012. J Clim 27:5075-5091

Li F, Wang H (2013) Autumn sea ice cover, winter Northern hemisphere annular mode, and winter precipitation in Eurasia. J Clim 26:3968-3981. https://doi.org/10.1175/JCLI-D-12-00380.1

Lin L, Gettelman A, Xu YY, Wu CL, Wang ZL, Rosenbloom N, Bates SC, Dong WJ (2019) CAM6 simulation of mean and extreme precipitation over Asia: sensitivity to upgraded physical parameterizations and higher horizontal resolution. Geosci Model Dev 12:3773-3793. https://doi.org/10.5194/gmd-12-3773-2019

Luo D, Xiao Y, Diao Y, Dai A, Franzke CLE, Simmonds I (2016a) Impact of ural blocking on winter warm Arctic-Cold Eurasian anomalies. Part II: the link to the North Atlantic oscillation. J Clim 29:3949-3971. https://doi.org/10.1175/JCLI-D-15-0612.1

Luo D, Xiao Y, Yao Y, Dai A, Simmonds I, Franzke CLE (2016b) Impact of ural blocking on winter warm Arctic-Cold Eurasian anomalies. Part I: blocking-Induced amplification. J Clim 29:3925-3947. https://doi.org/10.1175/JCLI-D-15-0611.1

Luo D, Yao Y, Feldstein SB (2012) Regime transition of the North Atlantic oscillation and the extreme cold event over Europe in January-February. Mon Weather Rev 142:4735-4757. https://doi. org/10.1175/MWR-D-13-00234.1

Watanabe D (2004) Asian jet waveguide and a downstream extension of the North Atlantic oscillation. J Clim 17:4674-4691

Mao R, Gong D, Yang J, Bao J (2011a) Linkage between the Arctic oscillation and winter extreme precipitation over central-southern China. Clim Res 50:187-201

Mao R, Gong D, Bao J, Fan Y (2011b) Possible influence of Arctic oscillation on dust storm frequency in North China. J Geogr Sci 21:207-218. https://doi.org/10.1007/s11442-011-0839-4

Mao R, Ho C, Shao Y, Gong D, Kim J (2011c) Influence of Arctic oscillation on dust activity over northeast Asia. Atmos Environ 45:326-337. https://doi.org/10.1016/j.atmosenv.2010.10.020

Matsuo K, Heki K (2012) Anomalous precipitation signatures of the Arctic oscillation in the time-variable gravity field by GRACE. Geophys J Int 190:1495-1506. https://doi.org/10.1111/j.1365246X.2012.05588.x

Miao H, Gong D, Mao R (2013) Possible influence of Febeuary-April Arctic oscillation on the ITCZ activity of Western-Central Pacific. J Trop Meteorol 29:55-65

Park TW, Ho CH, Yang S (2011) Relationship between the Arctic oscillation and cold surges over East Asia. J Clim 24:68-83

Park H, Ahn J (2016) Combined effect of the Arctic oscillation and the Western Pacific pattern on East Asia winter temperature. Clim Dyn 46:3205-3221. https://doi.org/10.1007/s00382-015-2763-2

Qi L, He JH, Zhang ZQ, Song JN (2008) Seasonal cycle of the zonal landsea thermal contrast and East Asian subtropical monsoon circulation. Chin Sci Bull 53(1):131-136

Qiao S, Hu P, Feng T, Cheng J, Han Z, Gong Z, Zhi R, Feng G (1990s) Enhancement of the relationship between the winter Arctic oscillation and the following summer circulation anomalies over central East Asia since the early 1990s. Clim Dyn 50:3485-3503. https://doi.org/10.1007/s00382-017-3818-3

Qu J, Gong D, Li S (2015) The possible influence of Arctic oscillation on South China Sea climate during boreal spring. Chin Sci Bull 60:2327-2337 
Rayner NA (2003) Global analyses of sea surface temperature, sea ice, and night marine air temperature since the late nineteenth century. J Geophys Res. https://doi.org/10.1029/2002JD002670

Saji NH, Goswami BN, Vinayachandran PN, Yamagata T (1999) A dipole mode in the tropical Indian Ocean. Nature 401:360-363

Simpkins G (2017) Progress in climate modeling. Nat Clim Change 7:684-685

Tao SY, Chen LX (1987) A review of recent research on the East Asian summer monsoon in China. In: Chang CP, Krishramurti TN (eds) Monsoon meteorology. Oxford University Press, Oxford, pp 60-92

Thompson DWJ, Wallace JM (1998) The Arctic oscillation signature in the wintertime geopotential height and temperature fields. Geophys Res Lett 25:1279-1300. https://doi.org/10.1029/98GL00950

Thompson DWJ, Wallace JM (2000) Annular Modes in the Extratropical Circulation. Part I: Month-to-Month Variability J Climate 13(5):1000-1016. https://doi.org/10.1175/1520-0442

Thompson DWJ, Wallace JM (2001) Regional climate impacts of the northern hemisphere annular mode. Science 293(5527):85-89. https://doi.org/10.1126/science.1058958

Thompson DWJ, Wallace JM, Hegerl GC (2000) Annular modes in the extratropical circulation. Part II: trends. J Clim 13(5):1018-1036. https://doi.org/10.1175/15200442

Wang B, Bao Q, Hoskins B, Wu GX, Liu YM (2008) Tibetan Plateau warming and precipitation changes in East Asia. Geophys Res Lett 35(14):702-706

Wang B, Wu RG, Fu XH (2000) Pacific-East Asian teleconnection: how does ENSO affect East Asian climate? J Clim 13(9):1517-1536

Wang B, Wu RG, Lau KM (2001) Interannual variability of the Asian summer monsoon: contrasts between the Indian and the western North Pacific-East Asian monsoons. J Clim 14(20):4073-4090

Wen C, Lihua K (2006) Linkage between the Arctic oscillation and winter climate over East Asia on the interannual timescale: roles of quasi-stationary planetary wave. Chin J Atmos Sci 30:863-870

Wen M, Yang S, Kumar A, Zhang P (2009) An analysis of the largescale climate anomalies associated with the snowstorms affecting China in January 2008. Mon Weather Rev 137:1111-1131. https ://doi.org/10.1175/2008MWR2638.1

Wu B, Wang J (2002) Winter Arctic oscillation, Siberian High and East Asian Winter Monsoon. Geophys Res Lett 29:1-3

Wu B, Bian L, Zhang R (2004) Effects of the winter AO and the Arctic Sea ice variations on climate variation over East Asia. Chin J Pol Res 16:211-220
Wu RG, Hu ZZ, Kirtman PB (2003) Evolution of ENSO-related rainfall anomalies in East Asia. J Clim 16(22):3742-3758

Yang H, Li C (2008) Influence of Arctic oscillation on temperature and percipitation in winter. Clim Environ Res 13:395-404

Yao J, Zhou T, Guo Z, Chen X, Zou L, Sun Y (2017) Improved performance of high-resolution atmospheric models in simulating the East Asian summer monsoon rain belt. J Climate 30:8825-8840

Zhang L, Zhu X, Fraedrich K, Sielmann F, Zhi X (2014) Interdecadal variability of winter precipitation in Southeast China. Clim Dyn 43:2239-2248. https://doi.org/10.1007/s00382-014-2048-1

Zhang Z, Gong D, Guo D, He X, Lei Y (2008) Anomalous winter temperature and precipitation events in Southern China. Acta Geogr Sin 63:899-912

Zhao P, Zhang RH, Liu JP, Zhou XJ, He JH (2007) Onset of southwesterly wind over eastern China and associated atmospheric circulation and rainfall. Clim Dyn 28(7):797-811

Zhao ZC, Luo Y, Huang JB (2018) The detection of the CMIP5 climate model to see the development of CMIP6 Earth system models. Clim Change Res 14:643-648 (in Chinese)

Zhou LT (2011) Impact of East Asian winter monsoon on rainfall over southeastern China and its dynamical process. Int J Climatol 31(5):677-686

Zhou TJ, Turner AG, Kinter JL et al (2016) GMMIP (v1.0) contribution to CMIP6: Global Monsoons Model Inter-comparison Project. Geosci Model Dev 9:3589-3604

Zhou TJ, Zou LW, Chen XL (2019) Commentary on the Coupled Model Intercomparison Project Phase 6 (CMIP6). Clim Change Res 15:445-456 (in Chinese)

Zuo J, Li W, Ren H (2012) Change of the relationship between spring NAO and East Asian summer monsoon and its possible mechnism. Chin J Geophys 55:384-395

Zuo J, Ren H, Li W (2015) Contrasting impacts of the Arctic oscillation on surface air temperature anomalies in southern China between early and middle-to-late winter. J Clim 28:4015-4026. https://doi. org/10.1175/JCLI-D-14-00687.1

Publisher's Note Springer Nature remains neutral with regard to jurisdictional claims in published maps and institutional affiliations. 